\title{
"Palabra de marino": el conocimiento de la costa meridional ibérica a la luz de la práctica de la navegación en la Era de los Descubrimientos (siglos XV-XVI)
}

\author{
'A Sailor's Word of Honor': Knowledge of the Southern Iberian \\ Coastline in Light of Navigational Practice in the \\ Age of Discovery (15th.-16th. Centuries) \\ Víctor MuÑoz Gómez \\ Instituto Universitario de Estudios Medievales y Renacentistas (Cemyr). \\ Universidad de La Laguna // Universidad de Valladolid \\ vmg1981@gmail.com
}

\section{RESUMEN}

Estudio de la topografía de la costa de Andalucía y de las condiciones de la navegación en ella a finales del Medievo e inicios de la Edad Moderna. Análisis a partir de diversos memoriales donde se describen los puertos y accidentes geográficos de esta costa y de sus fondos marinos, las condiciones para su reconocimiento y para una navegación segura por estas aguas. Su contenido detallado y eminentemente práctico se muestra un testimonio excepcional de la tradición profesional de los marinos castellanos, expertos en estas costas meridionales entre el Atlántico y el Mediterráneo, durante la época de los Descubrimientos.

Palabras clave: Historia Marítima. Corona de Castilla. Andalucía. Baja Edad Media. Topografía costera. Navegación.

\begin{abstract}
A study of Andalusia's coastline topography and conditions for navigation along it at the end of the Middle Ages and the beginning of the Early Modern Era. An analysis based on various records that offer descriptions of ports, land geography and the seabed of the coast. The conditions for their identification and for safe navigation in those waters. The detailed and extremely practical content of these texts attests to the professional tradition of Castilian sailors and their experience on the Southern Iberian coast, between the Atlantic Ocean and the Mediterranean, in the Age of Discovery.
\end{abstract}

Key words: Maritime History, Crown of Castile, Andalusia, Late Middle Ages, Coastal Topography, Navigation.

Sumario: 1. Introducción. 2. El conocimiento de la costa. Las fuentes: derroteros y memoriales. 3. El conocimiento de la costa. Para una topografía del litoral meridional ibérico. 4. Conclusión. 


\section{INTRODUCCIÓN}

Desde el año 2011, el grupo de investigación Castilla y el Mar de la Universidad de La Laguna se halla empeñado en el desarrollo del proyecto de investigación $D e$ mar a mar. Los puertos castellanos en la Edad Media, financiado por el Ministerio de Economía y Competitividad. Dentro de la ya dilatada trayectoria del grupo y sus miembros en el estudio de la Historia marítima de la Corona de Castilla en los siglos finales del Medievo', con este proyecto de investigación se planteaban unos objetivos bien definidos, concretables en varios aspectos. Por una parte, en la ajustada valorización del influjo que los procesos de urbanización e incremento de las actividades marítimas tuvieron en la vida de los puertos del reino, en el momento que se produjo la transformación de Castilla en una gran potencia europea y en el que triunfa el traslado de actividad naval y comercial desde el Mediterráneo hacia el Atlántico, entre los siglos XIV y XVI. Por otra parte, en la consideración de la influencia que pudieron tener estos lugares portuarios en el desarrollo de los espacios adyacentes y la medición de la misma a la hora de evaluar la conformación de hinterlands interdependientes con estos centros portuarios y la propia evolución de las áreas regionales en que se hallaban integrados tales puertos. Finalmente, en el análisis de la posible existencia de redes de intercambio económico en torno a estos puertos castellanos y su representación gráfica, poniendo en relación la conexión entre ellos y sus respectivos entornos a través de los diferentes medios de transporte de la época (terrestre, fluvial y marítimo).

No obstante, en este sentido es importante atender un aspecto sin duda relevante a la hora de comprender la articulación de tales redes portuarias y de intercambio marítimo: el estudio de la topografía costera castellana del final de la Edad Media y los inicios de la Edad Moderna. Y es que la incidencia de estos factores de orden geográfico en la práctica de la navegación en torno a aquellas costas no puede soslayarse ni tampoco la relación existente entre la actividad marinera y el nivel de conocimientos acerca de tales espacios marítimos y costeros manejado por las gentes de la época, sus formas de codificación y transmisión, etc. ${ }^{2}$.

*Abreviaturas utilizadas: Archivo General de Indias; AGS = Archivo General de Simancas; Archivo General Militar (Madrid) = AGM; En la España medieval $($ Madrid $)=$ EEM; Historia. Instituciones . Documentos $($ Sevilla $)=$ HID .

${ }^{* *}$ Este trabajo forma parte del proyecto de investigación De mar a mar. Los puertos castellanos en la Baja Edad Media (ref. HAR2010-17693), financiado por el Ministerio de Economía y Competitividad.

1 En relación a la trayectoria del grupo de investigación en este sentido, una breve exposición de sus principales hitos y resultados en el portal web del mismo: http://www.castillayelmar.com/historialinvestigador/ y http://www.castillayelmar.com/proyectos-de-investigacion/ (Consultado el 14-IV-2014).

2 Esta afirmación se sostiene sobre el convencimiento de que el análisis histórico no puede desatender a la condición volitiva de la relación entre las sociedades humanas y el espacio a lo largo del tiempo. Es decir, al carácter dinámico y cambiante de esa relación, fruto de la acción continua de los grupos humanos que habitan, explotan y conciben ese espacio, organizándolo y construyéndolo como tal. Sobre el interés del historiador como científico social por el desenvolvimiento de determinadas prácticas, conceptos y discursos que se integra dentro de dinámicas más profundas de génesis social del espacio y de encuadramiento en el mismo, algunas ideas cenitales en CERTEAU, Michel de: La invención de lo cotidiano. 1. Artes de hacer, México, Universidad Iberoamericana, 1996, 229 págs ( $1^{\mathrm{a}}$ ed. francés, París, 1980), sobre la noción de "lugar creado (p. 129), pero también en la formulación de "organización 
Huelga manifestar que una aproximación crítica a las fuentes documentales potencialmente útiles para estos fines es absolutamente necesaria. Por lo que respecta al estudio del fenómeno portuario medieval en el que fue uno de los ámbitos claves en la expansión marítima de Castilla en la Baja Edad Media (política, social, económica, cultural), el de la Andalucía atlántica ${ }^{3}$, algunos de los miembros del equipo de investigación tuvimos la ocasión de proponer una valoración de aquellas fuentes documentales de carácter "público" y "privado" disponibles para el análisis de esta temática dentro de este marco espacio-temporal. Conservadas en archivos y bibliotecas de diferente índole y titularidad, fue posible plantear un balance del grado de descripción y edición que se ha alcanzado de muchas de ellas hasta la fecha y del tratamiento historiográfico al que han sido sometidas tales fuentes ${ }^{4}$.

En ese estudio también hubo lugar a apuntar algunas de las posibilidades que, para la investigación futura, abría el tratamiento de la documentación de carácter gráfico, básicamente cartografía y dibujos de la costa, hasta la fecha no suficientemente

social del espacio" del profesor José Ángel GARCÍA DE CORTÁZAR, de influencia central en la evolución historiográfica del medievalismo español en los treinta años [GARCÍA DE CORTÁZAR, José Ángel, PorTELA, Ermelindo, CABrera, Emilio, GonzÁlez, Manuel, LóPEz de CocA, José Enrique: Organización social del espacio en la España medieval. La Corona de Castilla en los siglos VII a XV, Barcelona, Ariel, 1985, 248 págs.; García de CortÁzAr y Ruiz de AguirRe, J. Á.: "Organización social del espacio: propuestas de reflexión y análisis histórico de sus unidades en la España medieval", Studia Historica. Historia Medieval (Salamanca) 6 (1988) 195-236; IDEM: "Organización del espacio, organización del poder entre el Cantábrico y el Duero en los siglos VIII a XIII”, en García de Cortázar y Ruiz de Aguirre, J. Á. (ed.): Del Cantábrico al Duero. Trece estudios sobre organización social del espacio en los siglos VIII a XIII, Santander, 1999, pp. 15-48; IDEM, Sociedad y organización del espacio en la España medieval, Granada, Universidad de Granada-Universitat de València, 2004, 355 págs.].

${ }^{3}$ Dentro de la extensa bibliografía que, de un modo más o menos directo o tangencial ha atendido al factor marítimo en la evolución histórica del territorio del reino de Sevilla en la Baja Edad Media, citar aquí sólo algunos ejemplos señeros más directamente ligados a la configuración de su red portuaria, como pueden ser PÉREZ EMBID, Florentino: "Navegación y comercio en el puerto de Sevilla en la Baja Edad Media", Anuario de Estudios Americanos (Sevilla) 25 (1968) 43-94; GonzÁlez JiMÉNEz, Manuel, "La baja Andalucía en vísperas del descubrimiento", Canarias y América antes del Descubrimiento. La expansión europea. VII Jornadas de Estudios Canarias-América, Santa Cruz de Tenerife, Confederación Española de Cajas de Ahorros, 1985, pp. 109-147; Bernal Rodríguez, Antonio Miguel: Collantes de Terán SÁnchez, Antonio: "El puerto de Sevilla, de puerto fluvial medieval a centro portuario mundial (siglos XIV-XVII)", en CAVACCIOCHI, Simonetta (ed.): I porti come impresa economica. Atti della XIX Settimana di Studio, Florencia, 1988, pp. 779-824; Ladero Quesada, Miguel Ángel: "Puertos de Andalucía durante la Baja Edad Media: Sevilla y Málaga", en PolegGio, Ennio (ed.), Città portuali del Mediterraneo. Storia e Archeologia. Atti del Convegno Internazionale di Genova. 1985, Génova, 1989, pp. 133-140; González JimÉnez, M., Bello León, Juan Manuel: "El puerto de Sevilla en la Baja Edad Media (siglos XIII-XV), en ABUlafia, David, Garí, Blanca (ed.); En las costas del Mediterráneo occidental. Las ciudades de la Península Ibérica y del reino de Mallorca y el comercio mediterráneo en la Edad Media, Barcelona 1996, pp. 213-271; Aznar Vallejo, Eduardo: "Cádiz y su región en la expansión atlántica”, Estudios de Historia y Arqueología medievales (Cádiz) 10 (1994) 1123; Collantes de Terán SÁnchez, A.: "Papel del Atlántico en la configuración de Andalucía", HID, 35, 2008, pp. 85-105; Bello León, J. M., Martín Perera, Alejandro: Las atarazanas de Sevilla a fines de la Edad Media, Murcia, Editum. Ediciones de la Universidad de Murcia, 2012, 104 págs.

${ }^{4}$ Bello León, J. M., Muñoz Gómez, Víctor, González Zalacain, Roberto J.: "Nuevas propuestas con viejas fuentes: la documentación para el estudio de los puertos andaluces en la Época de los Descubrimientos", en XX Coloquio de Historia Canario-Americana, Cabildo de Gran Canaria-Casa de Colón, Las Palmas de Gran Canaria (en prensa). 
considerados en el estudio de la Historia marítima de la baja Andalucía medieval. Recientemente, hemos tenido la ocasión de volver sobre la cuestión de las fuentes por lo que se refiere a la cuestión que señalábamos del conocimiento topográfico de las costas atlánticas andaluzas entre los siglos XIV y XVI, la descripción de sus accidentes geográficos terrestres y marinos y de sus lugares portuarios, entre las que, precisamente, las fuentes cartográficas tienen un lugar extraordinariamente relevante. Considerábamos, pues una evaluación de algunas de las fuentes más idóneas para la aproximación al espacio geográfico marítimo andaluz bajomedieval y sus condiciones de navegación, ligadas a dinámicas estratégico-militares y mercantiles, y a las perspectivas de análisis historiográfico que suscitan. Muy concretamente, nos referíamos a tres bloques heterogéneos de fuentes. Primeramente, la documentación gráfica náutica por excelencia, cartas náuticas y portulanos. Seguidamente, los casos de derroteros y tratados y memoriales descriptivos para los ámbitos costeros andaluces. Finalmente, los casos de narraciones literarias de la época en las que se refieren viajes y acciones navales en la zona de interés en este estudio ${ }^{5}$.

El presente artículo proponemos un estudio empírico al respecto a partir de un testimonio documental de excepcional interés. Se trata de varios memoriales que hacen relación del estado y accidentes de la costa andaluza, conservados en el Archivo General de Simancas y el Archivo General de Indias. Redactados a mediados del siglo XVI a instancias de las autoridades de la Corona por razones presumiblemente estratégicas militares y comerciales, a partir de ellos es posible levantar una detallada topografía de las costas del sur de la Península Ibérica, desde el Algarve hasta el cabo de Palos. En aquéllos se recogen informaciones exhaustivas y de gran valor sobre los puertos, surgideros y accidentes geográficos de esta costa y de sus fondos marinos, además de sobre las condiciones para su reconocimiento y para la navegación segura por estas aguas. Su nivel de concreción y el contenido eminentemente práctico de estos documentos manifiesta el manejo en su confección de todo un conjunto de conocimientos que sólo podían corresponder a marinos expertos en este espacio náutico entre el Mediterráneo y el Atlántico, cuando no fueron directamente elaborados por estos navegantes. Unas personas que, en fin, era los depositarios de la herencia profesional reunida entre el final de la Edad Media y los inicios de la Edad Moderna en el ámbito meridional ibérico y, más concretamente, andaluz acerca de la geografía practicada de la costa del sur de la Corona de Castilla y de las condiciones y saberes para su navegación.

\section{EL CONOCIMIENTO DE LA COSTA. LAS FUENTES: DERROTEROS Y MEMORIALES}

En general, por lo que se refiere al estudio del espacio geográfico marítimo, físico y humano, andaluz en el tránsito entre la Edad Media y la Edad Moderna, puede

${ }^{5}$ Vid. MuÑoz GómEz, V.: "Fuentes para el estudio del litoral de la Andalucía atlántica en la Baja Edad Media. Una aproximación", en GonzÁlez Zalacain, R.J. (coord.): Actas de las V Jornadas 'Prebendado Pacheco'de Investigación Histórica, Tegueste, 2013, pp. 81-94; IDEM: "Para el conocimiento de la costa de la Andalucía atlántica (siglos XIV-XVI): descripciones, relaciones y documentación náutica", HID (Sevilla) 40 (2013), pp. 179-205. 
considerarse un marcado contraste entre por lo que se refiere al nivel de nuestros conocimientos sobre las costas de la Andalucía atlántica y las de la vertiente mediterránea, prácticamente coincidentes con el espacio bajo el dominio del sultanato nazarí de Granada hasta su conquista (1482-1492). Así, por lo que toca al litoral del reino granadino, la análisis combinado de informaciones extraídas de fuentes cartográficas junto con aquéllas otras procedentes de documentación escrita, muy especialmente notariales y privadas de tipo mercantil generadas por los mercaderes de origen italiano que operaban en el sultanato nazarí ${ }^{6}$, además de su contraste con los resultados obtenidos de la interpretación de los registros arqueológico en zonas costeras granadinas ${ }^{7}$, ha dado notables frutos. Ello permite hablar de una sobresaliente ampliación en estos últimos años del conocimiento del ámbito costero granadino islámico y de las sinergias económicas y sociales en él se experimentaron durante los últimos siglos del Medievo ${ }^{8}$. Sin embargo, aunque ya señalábamos que la atención

\footnotetext{
${ }^{6}$ Sin ánimo de ser exhaustivo, algunos títulos particularmente relevantes de esta tendencia pueden resultar los de GARí, B: "La advertencia del fin. Génova y el reino de Granada a mediados del siglo XV", en Presencia italiana en Andalucía. Siglos XIV-XVII. Actas del III Coloquio Hispano-Italiano, Sevilla 1989, p. 184; GARÍ, B, SAlicrú I Lluch, Roser: "Las ciudades del triángulo: Granada, Málaga y Almería, y el comercio mediterráneo en la Edad Media", en Abulafia, D, Garí, B (ed.): En las costas del Mediterráneo occidental..., pp. 171-211; FÁBREGAS GARCíA, Adela: "Estrategias de los mercaderes toscanos y genoveses en el Reino de Granada a través de la correspondencia Datini", Serta Antiqua et Mediaevalia. V Società e Istituzioni del Medioevo Ligure (Génova) 2001, 272; López De Coca CASTAÑer, J. E.: "Granada y la ruta de Poniente. El tráfico de frutos secos", en Malpica Cuello, Antonio (ed.): Navegación marítima del Mediterráneo al Atlántico, Granada 2001, pp. 151-177; FÁBregas GarCía, A.: "Redes de comercio y articulación portuaria del Reino de Granada: puertos y escalas en el tráfico marítimo bajomedieval", Chronica Nova (Granada) 30 (2003-2004) 69-102; GARCía Porras, Alberto, FÁBregas GARCIA, A.: "Genoese trade network in the southern Iberian peninsula: trade, transmission of technical knowledge and economic interactions", Mediterranean Historical Review (Londres) 25/1 (2010) 35-51; GonZÁLEZ ArÉvalo, Raúl: "Las galeras mercantiles de Florencia en el Reino de Granada en el siglo XV", Anuario de Estudios Medievales (Barcelona) 41/1 (2011) 125-149; IDEM: "Apuntes para una relación velada: la República de Florencia y el Reino de Granada en la Baja Edad Media”, Investigaciones de Historia Económica (Madrid) 8 (2012) 83-93.

7 Malpica Cuello, A., Gómez Becerra, Antonio: "La formación de un territorio fronterizo medieval: la costa granadina de la época musulmana a la conquista castellana", en III Coloquio de Arqueología Espacial. Fronteras, Teruel 1989, pp. 241-255; IDEM: "El poblamiento medieval de la costa oriental granadina", en Actas del III Congreso de Arqueología Medieval Española. Tomo II Comunicaciones, Oviedo 1992, pp. 313-319; IDEM: "Il traffico commerciale nel mondo mediterraneo occidentale alla fine del Medioevo: il Regno di Granada", en Alberini, Paolo (ed.): Aspetti ed attualità del potere marittimo in Mediterraneo nei secoli XII-XVI. Acta del Convegno di Storia Militare tenuto a Napoli, in Castel dell'Ovo, dal 27 al 29 ottobre 1997, Roma 1999, pp. 351-381; Malpica Cuello, A., Fábregas García, A.: "La vida marítima y el poblamiento medieval de la costa del Mediterráneo andaluz", en MALPICA Cuello, A. (ed.): Navegación marítima..., pp. 97-148; Malpica Cuello, A.: «Poblamiento y vida marítima en el reino de Granada: la pesca y la navegación», en D’Arienzo, Valdo, DA Selva, Biagio (eds.): Pesci, barche, pescatori nell'area mediterranea dal Medioevo all'Età Contemporanea, Milán, 2010, pp. 53-67.

${ }^{8}$ Una muestra muy actualizado de tal estado de la investigación histórica en torno a la costa del sultanato nazarí, capitalizada por el Grupo de Investigación "Toponimia, Historia y Arqueología del Reino de Granada", de la Universidad de Granada, en González Arévalo, R: "La costa del Reino de Granada en la documentación náutica italiana (siglos XIV-XVI)", EEM, 31 (2008) 7-36; o MaLPICA Cuello, A., Fábregas García, A.: "Embarcaderos y puertos en la costa del reino de Granada", en FÁbregas García, A. (ed.): Navegación y puertos en época medieval y moderna, Granada, 2012, pp. 75-109.
} 
historiográfica dedicada al desarrollo portuario de la baja Andalucía durante el final de la Edad Media no ha sido menor 9 , este mismo bagaje, por lo que respecta a la geografía costera de este territorio durante la Baja Edad Media y al conocimiento que de la misma manejaban los contemporáneos en relación con la práctica de la navegación, ha tenido un alcance bastante más discreto hasta la fecha. En este sentido, en cuanto a trabajos que se han ocupado de esta problemática y han recurrido al manejo de noticias cartográficas y documentales, pueden citarse los artículos de Carlos Gozalbes Cravioto, centrados en el área del estrecho de Gibraltar ${ }^{10}$, o el dedicado por Raúl González Arévalo al conjunto de la costa del reino de Sevilla, basándose en el análisis de documentación náutica florentina fechada entre el final del siglo XVI y mediados del siglo XVI - un total de siete cartas, además del conocido Compasso a mostrare a navicare de Uzzano ${ }^{11}$. Los resultados de tales estudios no dejan de ser ciertamente interesantes, al aportar unos primeros datos acerca de la presumible jerarquía de los puertos y accidentes geográficos de la zona considerados por los navegantes que participaban en las grandes rutas marítimas a grande distancia y su puesta en relación con otras etapas señeras del comercio italiano en el ámbito ibérico, norteafricano y hacia el Atlántico ${ }^{12}$. En cualquier caso, esta línea de investigación ha de ser aún explorada en profundidad, cometido en que se hallan empeñados algunos de los esfuerzos del proyecto De mar a mar que más arriba mencionábamos.

En este sentido, precisamente aquellos documentos que ofrecen relaciones descriptivas más o menos detalladas de los puertos, surgideros y accidentes físicos

9 Vid. nota 3.

10 Gozalbes Cravioto, C.: "La costa del campo de Gibraltar en los portulanos medievales", Almoraima. Revista de estudios campogibraltareños (Algeciras) 13 (1995) 163-174; IDEM: "Tarifa en la geografía medieval. Fuentes textuales (I)", Aljaranda. Revista de estudios tarifeños (Tarifa) 54 (2004) 7-12; IDEM: "Tarifa en la geografía medieval. Las fuentes cartográficas (y II)", Aljaranda. Revista de estudios tarifeños (Tarifa) 55 (2004) 5-10. La fuente fundamental para estos estudios es un elenco de hasta veintitrés portulanos datados entre los inicios del siglo XIV y el año 1501.

${ }^{11}$ González Arévalo, R: "La costa del reino de Sevilla en la documentación náutica italiana (siglo XV), en Malpica Cuello, A., Peinado Santaella Rafael G., Fábregas García, A. (eds.), Historia de Andalucía. VII Coloquio, Granada, 2010, CD-Comunicaciones, pp. 301-317. El Compasso a mostrare a navicare dall'uno stretto all'altro, incluido dentro de la Prattica de la Mercatura de Giovanni di Antonio da Uzanno, redactado en 1442 [PAgnini del Ventura, Giovanni: Della decima e di varie altre gravezze imposte dal Comune di Firenze. Della moneta e della Mercatura de fiorentini fino al secolo XVI, vol. IV: Contenente la Pratica della Mercatura scritta da Giovanni di Antonio da Uzzano (nel 1442), LisboaLucca, 1766 (facsímil de Forni Ed., vol. II, Bolonia, 1967, pp. 199-276)], es una fuente fundamental para el estudio de las rutas de navegación italianas del final de la Edad Media y que ha sido manejado en múltiples estudios, entre los que, para los intereses de este trabajo en relación a la descripción de los espacios costeros ibéricos, merece la pena citar el de Igual LuIs, David: "Itinerarios comerciales en el espacio meridional mediterráneo de la Baja Edad Media", Itinerarios medievales e identidad hispánica: XXVII Semana de Estudios Medievales, Estella 17 a 21 de julio de 2000, Pamplona, 2001, pp. 113-158.

${ }_{12}$ En esta línea de aportaciones, habrá que tener en cuenta la ponencia recientemente presentada por la investigadora francesa Emmanuelle VAGNON con el título "Le détroit de Gibraltar dans les cartes marines européennes du $\mathrm{XV}^{\mathrm{e}}$ et $\mathrm{XVI}^{\mathrm{e}}$ siècle: toponymie et iconographie", en el marco del coloquio Estrechos. encontradas sobre la imagen del Estrecho de Gibraltar (Antigüedad y Edad Media), celebrado en la Casa de Velázquez (Madrid) los días 11 y 12 de abril de 2013. La publicación surgida de esta reunión científica puede ser de gran interés en la contribución del tema que nos ocupa en estas páginas. Más información al respecto en www.casadevelazquez.org/es/investigacion/novedad/ estrechos-1/ (consultado 6-IV-2014). 
del litoral constituyen sin duda un conjunto de fuentes de sobresaliente importancia por lo que se refiere al conocimiento al conocimiento de la geografía costera y marítima andaluza entre el final de la Edad Media y los inicios de la Edad Moderna. Uno de sus principales atractivos radica en la inclusión, junto con estos datos, de otros de más puntual interés para la singladura por estas costas y cuya obtención por sus autores es el fruto de la recopilación de experiencias prácticas en el ejercicio de la navegación por ellas, bien de forma directa por parte de sus autores, bien a causa de su transmisión por parte de marinos veteranos en esos mares. Es el caso de las distancias calculadas entre los puntos descritos en tales relaciones, los regímenes de vientos y corrientes activos en las costas y en las entradas de los puertos, las calidades estimadas de los fondeaderos, las características de los fondos marinos o la presencia de escollos, bajíos y de otros peligros para la integridad de los navíos que operasen en esos litorales. Ese carácter eminentemente técnico y práctico induce a que sus informaciones hayan de ser tenidas muy en cuenta como testimonios veraces del estado de conocimientos resultante al final de la Edad Media acerca de las costas meridionales ibéricas.

Ha de reconocerse que, por lo que respecta al ámbito andaluz, apenas han llegado hasta nosotros documentos castellanos de estas características. Afortunadamente podemos citar al menos tres, datados ya en el siglo XVI. Su contenido permite ponerlos en relación con la tratadista hispana de materia náutica e hidrográfica aparecida a partir de este $\operatorname{siglo}^{13}$, como es el caso de la Suma de Geographia de Martín Fernández de Enciso (1519) o la Hydrografia de Andrés de Poza (1585) ${ }^{14}$, pero no tanto por la detección de influencias no corroboradas en los autores de nuestros documentos a partir la lectura de determinadas obras impresas de esta naturaleza.

${ }^{13}$ No tenemos noticia de la redacción de obras de estas características con anterioridad al siglo XVI, comparables a libros portulanos o roteros como el ya citado Compasso a mostrare a navicare... italiano o el Grand routtier et pyllotage et encrage de la mer... elaborado por el gascón Pierre Garcie entre 1483 y 1484 (GARCIA, Pierre, dit Ferrande: Le grand routtier et pyllotage et encrage de la mer ... tant ses parties de France, Bretaigne, Angleterre, Espaigne, Flandres, haultes Allemaignes, avecques les dangers des ports, havres, rivières, chenal des parties \& régions susdites, Poitiers, 1521; http://gallica.bnf.fr/ ark:/12148/bpt6k54143h.r=pierre+garcie+dit+ferrande.langES, consultado el 14-V-2013). En el caso portugués, el desarrollo de la exploración de las costas africanas desde mediados del siglo XV también dio lugar, además de a su plasmación cartográfica, a un interesante despliegue de obras de contenido científico y técnico ya desde el siglo XVI. Para una aproximación a la cartografía y la tratadística náutica ibérica, castellana y portuguesa, vid. CoRTESÃo, Armando (ed.): História da cartografia portuguesa (Vol. 2. Con dois capitulos sobre História de Náutica), Lisboa, Junta de Investigações de Ultramar, 1970, Vol. 2; Cerezo Martínez, Ricardo: La Cartografia Náutica Española en los Siglos XIV, XV y XVI, Madrid, Consejo Superior de Investigaciones Científicas 1994, 306 págs.; MARQUES, Alfredo Pinheiro: "La cartografía portuguesa en la era de los Descubrimientos / The portuguese cartography in the era of Discoveries", en Atlas Universal de Diogo Homen, Barcelona, 2002, pp. 11-213.

${ }^{14}$ El proyecto Dicter 2.0, coordinado desde el Centro de Investigaciones Lingüísticas de la Universidad de Salamanca para la elaboración del Diccionario de la Ciencia y la Técnica del Renacimiento español, ha reunido en su portal web un total de setenta y cuatro tratados científico-técnicos elaborados a lo largo del siglo XVI y el primer cuarto del siglo XVII y clasificados en doce áreas temáticas, todos ellos consultables en versión digital. Entre ellos, se consideran, dentro de las áreas de Cosmografía y Geografía y de Náutica y Arquitectura Naval, hasta catorce textos, entre ellos los arriba citados. Para mayor información acerca del proyecto, de la literatura náutica hispana de la Alta Edad Moderna y de estas obras, véase http://dicter.eusal.es/ (consultado 8-IV-2013). 
Más bien, lo que puede observarse es su integración en un dinámica común de tradiciones y conocimientos marineros que hundían sus raíces en la Edad Media y que estaban cristalizando, normalizándose y transmitiéndose en forma escrita a partir del Renacimiento en España, propiamente en un contexto político, social, económico y cultural dominado por la expansión, conquista y colonización americana y por la incrementación de poderes monárquicos estatalistas de raíz autoritaria, a caballo entre el Medievo y la Modernidad ${ }^{15}$.

Justamente, fue la iniciativa de las autoridades de la Corona por recabar este tipo de informaciones acerca de las costas de la monarquía de España la que se halló detrás de la elaboración de los documentos, tres memoriales, que he apuntado. Iniciaremos su estudio comenzando por el más antiguo de ellos. Se trata del confeccionado a finales de 1526 a instancias del veedor de las fortalezas y gentes de guerra del reino de Granada Ramiro Núñez de Guzmán. Entre la abundante documentación generada por su misión de inspección de las guarniciones y defensas del reino frente a la amenaza de sublevaciones moriscas y al peligro que suponía el corso berberisco ${ }^{16}$, se encuentra esta relación, que nos ofrece una muy puntual descripción de las costas mediterráneas de la Corona de Castilla, incluido el reino de Granada, entre el cabo de Palos y Gibraltar ${ }^{17}$.

Efectivamente, la Memoria de los puertos y calas que ay desd'el cabo de Palos hasta la punta del Carnero que es junto con Gibraltar y el Estrecho, adonde se pueden abrigar navios de rremos, fustas y galeras, tal y como es intitulado de forma ilustrativa el documento, numera los principales accidentes geográficos, puertos y surgideros de las costas del reino de Murcia y del reino de Granada con un extraordinario nivel de detalle. Así, esta memoria se estructura de este a oeste, considerando los distintos lugares enumerados de acuerdo con los siguientes aspectos. Por una parte, su distancia

${ }^{15}$ Un acercamiento actualizado al fenómeno de la expansión atlántica europea bajomedieval y altomoderna desde la óptica hispana en Díaz de Durana Ortiz de Urbina, José Ramón, Munita Loinaz, José Antonio (ed.): La apertura de Europa al mundo atlántico. Espacios de poder, economía marítima y circulación cultural, Bilbao, 2011.

${ }^{16}$ En relación esta misión en concreto y, en general, a la organización de la defensa costera del reino de Granada en desde la época de los Reyes Católicos y en el siglo XVI, vid. LóPEZ DE CoCA CASTAÑer, J. E.: "Financiación mudéjar del sistema de la vigilancia costera en el Reino de Granada (1492-1501)", HID, 3 (1976) 397-416; IDEM, "Consideraciones sobre la frontera marítima", en Segura ARTERo, Pedro (ed.): Actas del Congreso La Frontera Oriental Nazarí como Sujeto Histórico (S.XIII-XVI). LorcaVera, 22 a 24 de noviembre de 1994, Almería, 1997, pp. 391-408; JimÉnez Estrella, Antonio: "La Capitanía General del reino de Granada durante el reinado de Carlos V", en Castellano Castellano, José Luis, SÁnchez-Montes GonzÁlez, Francisco (eds.): Carlos V. Europeísmo y Universalidad. Vol. II. La organización del poder, Madrid, 2001, pp. 339-368; IDEM: Poder, ejército y gobierno en el siglo XVI. La Capitanía General del Reino de Granada y sus agentes, Granada, Universidad de Granada, 2004. 514 págs.

17 AGS, Cámara de Castilla. Diversos, $C^{\mathrm{a}} .44, \mathrm{n}^{\circ} .15$. La relación recogida en este interesante documento puede ser contrastada con otros documentos contemporáneos expresivos de la importancia concedida a determinados puntos costeros granadinos, a razón del establecimiento de guardas para su vigilancia y defensa (vid. AGS, Cámara de Castilla. Diversos, Ca . 44; AGS, Cámara de Castilla, Libros de Cédulas, no. 27, ff. 33v.-55v., editado en Arroyal Espigares, Pedro, Cruces Blanco, Esther, Martín Palma, María Teresa: Cedulario del reino de Granada (1511-1514), Málaga, Universidad de Málaga, 2008, pp. 91-119, citado en Malpica Cuello, A, Fábregas García, A: "Embarcaderos y puertos...", pp. 89-92). 
en leguas, tanto al este como al oeste, con respecto al puerto mayor más próximo, entendiéndose como tales Cartagena, Almería y Málaga ${ }^{18}$. Por otra, el régimen de vientos con el que cada uno de estos puertos y surgideros podía ser practicado para acceder a él. Además de todo ello, habitualmente se menciona la calidad esos lugares para fondear y surgir con los vientos señalados como propicios para ello, en términos como ...buena de... o ...razonable de..., y, de manera más excepcional, se recoge su aptitud para determinados tipos de navíos ${ }^{19}$.

Las informaciones vertidas en el documento denotan el concurso de un marino versado en el conocimiento práctico de este litoral y en los saberes náuticos de tradición mediterránea ligados a la navegación en esta zona. Prueba de ello es su minuciosidad a la hora de nombrar hasta calas de entidad muy menor y sus condiciones náuticas precisamente para navíos de propulsión mixta, a vela y remos, típicos de estas aguas. Más aún, esta experiencia puede apreciarse a partir de la citación de los vientos siempre por su denominación mediterránea, reconociéndose justamente aquéllos que operaban en la zona del Estrecho y el mar de Alborán: levante $(\mathrm{E})$, poniente $(\mathrm{O})$ y vendaval ( $\mathrm{SE}$ o $\mathrm{SO}$ ). Igualmente, las orientaciones geográficas de cada uno de los lugares respecto a los tres puertos principales señalados son aportadas bajo nomenclatura mediterránea, levante o poniente.

Muestra también de la condición de práctico del informante de la relación puede encontrarse en que, en cualquier caso, es la costa entre el cabo de Palos y el sector oriental del reino de Granada, hasta La Herradura en Almuñécar, la que es referida con todo lujo de detalles. Mientras, la descripción del litoral entre este último puerto y Gibraltar se despacha sin mención a ningún otro fondeadero o accidente geográfico cuando su existencia desde época islámica era notoria, como podían ser los casos de Fuengirola, Marbella o Estepona ${ }^{20}$. Estas ausencias apuntan a los propios factores a los que pudo obedecer la elaboración del documento y, vinculado a ello, el acceso a la fuente de información. Esto es, la priorización, dentro de la coordinación de la defensa costera del reino granadino, de la incidencia del corso berberisco en las zonas más orientales del mar de Alborán, dentro de un eje de vigilancia de la costa por parte de los navíos reales que pivotaba sobre los puertos de Cartagena, Almería y Málaga, el cual afectaba igualmente al reino de Murcia si bien escapaba a su atención el litoral mediterráneo más occidental hasta el Estrecho. Atendiendo a tal área de interés por parte del veedor militar para el reino de Granada, puede comprenderse la consulta para la redacción de la relación a marinos expertos en el cabotaje de esta zona entre el cabo de Palos y Málaga. Precisamente, la especialización en esta costa de la fuente de información de la que las autoridades reales dispusieron, sin más, pudo condicionar

18 Tres ejemplos de ello: Maçarrón: bueno de poniente; siete leguas de Cartajena para poniente AGS, Cámara de Castilla. Diversos, C $.44, n^{\circ} .15$, f. 1 r.); Las Albuferas: buenas de todos tienpos; siete leguas a poniente de Almería (ibidem, f. 1 v.); Gibraltar: veynte leguas a poniente de Málaga; bueno de levante (ibidem, f. 2 r.).

19 Otros tantos ejemplos: L'Azubía: bueno de todos tienpos para navios de remos (ibidem, f. 1 r.); Almería: buena de levante; XXIX leguas a poniente de Cartajena (ibidem, f. 1 v.); La Cala del Arena: buena de poniente y razonable de levante; catorze leguas de Almería hazia poniente (ibidem, f. 2 r.).

20 González Arévalo, R.: "La costa del Reino de Granada..., pp. 27-28; Malpica Cuello, A., FÁbregas García, A.: “Embarcaderos y puertos...”, pp. 86, 88-90. 
el vacío para el área a poniente de la ciudad de Málaga en esta relación ${ }^{21}$.

Pasando al segundo de estos memoriales, se puede datar poco después de $1554 \mathrm{y}$, por su contenido, puede deducirse que fue redactado por el patrón o el piloto de una de las naos que participó en el socorro de las tropas del emperador Carlos V comandado por Alonso Luis de Lugo, tercer adelantado mayor de Canarias, a la ciudad de Calvi, en Córcega, sitiada por los franceses y los turcos ${ }^{22}$. Se presenta como una Relaçión de los puertos y cauos de la costa de España desde el cauo de Ysuer en Fuenterrauía al estrecho de Gibraltar y adelante, pero recoge datos en este sentido correspondientes a toda la Península Ibérica y a todo el Mediterráneo occidental, comprendiendo también las costas del sur de Francia, las de la Península Itálica bañadas por el mar Tirreno y las del norte de África entre Ceuta y Túnez, además de las de las islas y archipiélagos que se encuentran en esta cuenca ${ }^{23}$. Todo indica que esta memoria fue requerida a instancias de alguno de los consejos principales de la monarquía española -Estado o Guerra, presumiblemente- como una información técnica necesaria para la protección de los intereses estratégicos marítimos de la Corona en esa zona del Mediterráneo.

Que nos encontramos de nuevo ante la exposición de los conocimientos de un navegante experimentado en estas aguas es algo que viene reflejado por distintos elementos recogidos en la relación. El más expresivo de todos acaso sea la propia declaración de su autor, reconociendo que el informe redactado es el fruto de su propia experiencia náutica en estas costas, levantado sin el concurso de cartas ni libros de derrota, asumiendo las posibles inexactitudes menores en la medición de las distancias y de los rumbos a seguir o el olvido a la hora de consignar alguno de los lugares

${ }^{21}$ No hay que dejar de lado tampoco la incidencia, en la percepción del espacio costero granadino, que pudo tener la reorganización del poblamiento en determinadas comarcas de ese reino tras su conquista a causa del despoblamiento parcial de algunas de ellas a causa de la emigración de parte de la población morisca al norte de África, de la continuidad de la amenaza de este corso y de los contactos mantenidos entre los moriscos con los piratas. Vid. nota 16 y López de COCA CASTAÑER, J. E.: "Granada y el Magreb: la emigración andalusí (1485-1516)", en García Arenal, Mercedes, Viguera, María Jesus (eds.): Relaciones de la Península Ibérica con el Magreb (siglos XIII-XVI). Actas del coloquio (Madrid, 17-18 de diciembre, 1987), Madrid, 1988, pp. 409-451.

${ }^{22}$ Las noticias respecto a la intervención del adelantado Alonso Luis de Lugo en Córcega son bien conocidas (vid. Fernández Duro, Cesáreo: Armada española desde la unión de los reinos de Castilla $y$ de León, 9. Vols., Madrid, 1895-1903, Vol. I., p. 290). A partir de la mención que se hace en el documento al socorro de Calvi [Calui, que se defendió de la armada del Turco e Françia e yo entré con socorro de gente <con> vna nao ynfanta de España, ano de 54. (vid. nota 23)], se intentó sondear la posible identidad del autor de la relación en caso de que pudiera tratarse del mismo adelantado o de alguno de los oficiales de la flota que hizo el transporte a Córcega. Un primer acercamiento a la documentación simanquina sobre esta acción de armas no ha dado resultados positivos, no habiéndose localizado nexo entre este memorial y el adelantado de Canarias (AGS, Catálogo de Diversos, $\mathrm{n}^{\circ}$. 1.206, 1.221) ni tampoco noticias sobre la intervención de una nao ynfanta de España entre algunas de las que sí se han podido documentar empeñadas en el transporte de tropas a Calvi (AGS, Estado España, leg. 104; Estado Génova, leg. 1.383, ff. 263-264). Tal vez una investigación más profunda en los papeles del Consejo de Estado en Simancas y en Archivo Histórico Nacional pueda dar mejores frutos. Quiero, en todo caso, agradecer a Patricia Rodríguez Rebollo, investigadora y amiga, su ayuda y orientación acerca de estos fondos en relación con este asunto.

${ }^{23}$ AGI, Indiferente General, $C^{\mathrm{a}} .1 .528, \mathrm{n}^{\circ} 39$. 
marítimos del litoral descrito ${ }^{24}$. No es, de todos modos, el único factor a considerar a este respecto. Así, el relator recoge los principales accidentes geográficos y puertos en todo el espacio descrito, consignando las distancias en leguas que separaban cada uno de ellos respecto del punto costero anteriormente señalado ${ }^{25}$. Además, se indican los rumbos de derrota por el litoral también, para lo cual son referidas las direcciones de los vientos mediante nomenclatura atlántica (este, oeste, etc.) y, en ocasiones, algunas mediciones en grados para el seguimiento del rumbo respecto a la costa. Todo ello es muy ilustrativo del horizonte de conocimientos náuticos manejado por autor en el momento de redacción y de la propia amplitud de su experiencia de navegación. No obstante, las noticias aportadas acerca del reconocimiento del litoral y sus hitos reseñables, como podremos observar por lo que toca a las costas del sur ibérico, tienen un carácter fundamentalmente sumario. El autor de esta relación proporciona una síntesis de aquellos puertos y accidentes geográficos considerados a su juicio de mayor relevancia para el ejercicio de la navegación en un espacio practicado extraordinariamente amplio, alejado del grado de detalle que hallamos en la Memoria de 1526 para la costa del mar de Alborán, Con todo, incluso por esa misma lógica de síntesis basada en la experiencia personal que se aprecia en la relación aportada por este marino ante la solicitud realizada por los organismos de gobierno de la monarquía, estamos ante un testimonio sobresaliente de las prácticas marineras de la época, que pueden asociarse, insistimos, con la acumulación de saberes en gran medida empíricos relativos al cabotaje de las costas peninsulares entre el final de la Edad Media y los inicios de la Edad Moderna.

Por lo que toca al último de los documentos, es poco más tardío que el anteriormente citado, algo posterior a 1555, al señalarse en su relación la referencia al desastre sufrido ese año en el golfo de Cádiz por la flota de la carrera de Indias capitaneada por Cosme Rodríguez Farfán, al desperdigarse el convoy en el tornaviaje desde América a causa de una tempestad y perderse buena parte de los barcos, los cuales naufragaron, quedaron varados o simplemente desaparecieron en el mar en un área tan vasta como la comprendida entre el estuario del Tajo, frente a Lisboa, y la isla de Tarifa ${ }^{26}$. Probablemente se trate de la descripción más detallada del conjunto de la

${ }^{24}$ Así, concluye el autor su relación diciendo: Esta relación se a echo a discreción y la memoria del honbre es holbidadizo, y avn que todas las partes $q<u e>$ aquí ago memoria, landado e estado/, por aber escripto sin carta de marear ni libros de derrotas y legoas de vna punta a otra podría ser lo errase en alguna parte en las leguas $i$ vn cuarto de viento a vna parte o a otra, y otras que por no tener en memoria se dexan escriuir lugares de la marina y legoas; la falta V. S. perdone.(ibidem, f. 3v.)

${ }^{25}$ De este modo, las costas ibéricas se describen, rodeando toda la península, desde el cabo Higuer, en el extremo este del Cantábrico, hasta Roses, en el norte de Cataluña. Por tanto, para el Algarve, Andalucía y Murcia, la relación de lugares en el litoral se hace de oeste a este, con un tenor similar al que puede mostrarse en el siguiente ejemplo, para la costa entre el cabo San Vicente y Cádiz: Del cauo de San Vicente al cauo de Santamarýa, la costa al est'oeste y lo mismo hasta el cauo de Sanlúcar de Varrameda, ay cincuenta leguas y sietea Cádiz -57-. Son 97 leguas (ibidem, f. 1 r.).

${ }^{26}$ El tornaviaje de la flota de Cosme Rodríguez Farfán desde América a España terminó convirtiéndose en una tragedia mayúscula a causa de la pérdida de un buen número de barcos, de la carga transportada y de vidas, incluida la San Andrés, nao capitana de Farfán frente a la playa de Zahara el 22 de enero de 1555. Estos acontecimientos, sin embargo, han dejado una importante huella documental, en buena medida por la investigación que motivó el descubrimiento de que la San Andrés transportaban grandes cantidades de metales preciosos no declarados, fraude en el que actuaron en connivencia el mismo 
costa del golfo de Cádiz, entre el cabo de San Vicente y Gibraltar de la que tenemos noticia con anterioridad al final del siglo XVI, resultando aún más exhaustiva que la posteriormente recogida para esta región por el licenciado Andrés de Poza en su Hydrografia de1585, tratado éste que podría ser el texto que mejor se presta a una comparación de las informaciones vertidas en esta relación conservada en el Archivo General de Indias ${ }^{27}$. Resulta difícil precisar los motivos que condujeron a su elaboración pero de nuevo hay que pensar en un requerimiento emanado del aparato de gobierno polisinodial de la monarquía española, esta vez vinculado acaso con el control del tráfico naval hacia Indias, que se traduciría en una información general sobre los puertos y barras del litoral atlántico del Algarve y de Andalucía. La precisión técnica en sus informaciones lleva a pensar que su autor fuera un buen entendido en la tratadística náutica del siglo XVI y de los saberes reglados y prácticos manejados por los pilotos veteranos en la navegación en esta costa, lo que podría apuntar hacia un marino andaluz u otra persona con conocimientos navales y cosmográficos reconocidos ligada de algún modo al entorno de la Casa de la Contratación de Sevilla ${ }^{28}$.

La Relación de los puertos y barras... expuesta por el autor se corresponde con fidelidad a la descripción que hace de la misma en su inicio, por más que aquélla

capitán de la flota, el propietario de la nao y algunos importantes magistrados de la Audiencia del Nuevo Reino de Granada. Sobre el viaje y naufragios de la flota, vid. AGS, Cámara de Castilla. Diversos, $C^{\mathrm{a}} .40, \mathrm{n}^{\mathrm{o}} 67$ (6); AGI, Contratación, leg. 2.000 y 5.108; AGI, Consulado, leg. 841, nº 5; Catálogo de la Colección de don Juan Bautista Muñoz. Documentos interesantes para la Historia de América. Tomo II, Madrid, 1955, pp. 278, 289, 297, 304-306, 309-310, 315, 317-318, 481-482; Lorenzo SANZ, Eufemio: Comercio de España con América en la época de Felipe II, Valladolid, 1979, Vol. II, p. 390; Flores Moscoso, Ángeles: "Naufragios en el golfo de Cádiz", en Torres Ramírez, Bibiano, Hernández Palomo, José J. (ed.): Andalucía y América en el siglo XVI. Actas de las II Jornadas de Andalucía y América, [celebradas en la] (Universidad de Santa María de la Rábida, marzo, 1982), Sevilla, 1983, Vol. I, pp. 333-360, en concreto pp. 349-352; Pérez Mallaína Bueno, Pablo Emilio: El hombre frente al mar. Naufragios en la Carrera de Indias durante los siglos XVI y XVII, Sevilla, 1996, pp. 43, 89, 91.

A la hora de determinar una posible datación del documento, a resultas de la consulta de la bibliografía citada, el autor de la relación no refleja ninguna referencia a otros naufragios posteriores sufridos en el golfo de Cádiz o al remontar el Guadalquivir hacia Sevilla por las naves de la carrera de Indias, que se conocen por ejemplo para 1561, 1563 y 1592. Tampoco se aprecia en el contenido del texto un posible influjo a partir de las de las descripciones hidrográficas de las costas atlánticas hispanas que aparecen en el tratado de Andrés de Poza impreso en 1585 (PoçA, Andrés de: Hydrografia la mas curiosa que hasta aqui ha salido a luz : en que de mas de vn derrotero general, se enseña la nauegacion por altura y derrota, y la del Este Oeste: conla Graduacion de los puertos, y la nauegacion al Catayo por cinco vias diferentes, compuesto por el Licenciado Andres de Poça, Bilbao, Matías Mares, 1585, Libro Segundo, Capítulos I-VI, ff. 2 v.-21 r.). Aunque paleográficamente el tipo de letra manejado puede plantear alguna duda, referencias a estimaciones de distancia con expresiones como ...va de luengo de la costa de las Harenas Gordas obra de vn tiro de arcabuz... (vid. infra, nota 27, f. 3 r.) o ...que es limpio y estarán vn tiro de lombarda de tierra. (ibidem, f. 1 r.), en combinación con los otros argumentos que aportamos, invitan a considerar que la descripción original estuviera fechada en el tercer cuarto del siglo XVI, aunque posiblemente el documento pudiera ser una copia bastante posterior de la misma.

${ }^{27}$ AGI, Indiferente General, $C^{\mathrm{a}}$. 1.528, $\mathrm{n}^{\mathrm{o}} 44$.

${ }^{28}$ Puede resultar ilustrativo de ello el encabezamiento que hace del documento el autor: Relación de los puertos y barras que ay en la costa dende el cabo de Sant Vicente hasta el cabo de Trafalgar y las señales de tierra que sobre los dichos puertos ay y el fondo y señales de sonda que assimismo tiene cada puerto y remitiéndome a algún mejor rotero que en ello puede auer en alguna parte d'ella. (ibidem, f. 1 r.). 
se extienda más al sur de cabo Trafalgar hasta alcanzar Gibraltar. En efecto, nos encontramos ante una pormenorizada memoria de los accidentes geográficos de esta costa y de sus puertos y fondeaderos señeros, aportando toda suerte de detalles sobre las referencias a considerar para su práctica. Así, notifica las distancias entre puntos en leguas, las calidades de puertos, los regímenes de corrientes y vientos a tener en cuenta para la navegación de cabotaje y la entrada y salida en los surgideros, además de los potenciales peligros que se encontraban en el litoral por la presencia, fundamentalmente, de bajas en zonas habitualmente transitadas por los navíos que surcaban el litoral del golfo de Cádiz. Junto con la consideración altamente exhaustiva de los que apunta como surgideros, adras y barras adecuados para ser practicados, dependiendo del calado de las naves, en las costas del Algarve y de la Andalucía atlántica $^{29}$, otros aspectos recogidos en la relación pueden valorarse como de sumo interés.

Así, resultan de particular significación las múltiples referencias que el autor aporta para el reconocimiento desde el mar de los lugares de la costa. No son, en este sentido, extrañas, las alusiones a elementos destacados de la orografía del litoral, cuyo reconocimiento se estima de ayuda para una mejor orientación del navegante, tales como la presencia de montañas visibles desde los navíos en el mar $^{30}$. A la par de ello, hay que subrayar la consignación detallada de distancias entre el mar y la costa y, asociadas a esto mismo, de las referencias a las condiciones de los fondos marinos, basadas en dos aspectos ${ }^{31}$. Por un lado, la toma de sondas de tales fondos, que permitían reconocer la profundidad de los mismos, medida en brazas, y la composición de sus materiales, que se recoge en este documento por primera vez para toda la costa descrita, hasta donde nosotros tenemos constancia ${ }^{32}$. Por el otro, a su vez ligado con todo lo antes citado respecto al reconocimiento de los relieves de la

${ }^{29}$ Así se advierte para las barras de Tavira y de Ayamonte como aptas sólo para navíos de hasta 50 y 100 toneladas, respectivamente (ibidem, ff. 2 r.-v.), o la de Barbate, indicada como para ... barcos pequeños... (ibidem, f. 5 v.). Mientras, los fondeaderos amplios y seguros son nombrados con expresiones como la, por ejemplo, utilizada para la bahía de Cádiz, que ... es muy grande para muchas naos; y más adentro, donde dizen el Puntal, está otra baýa muy capaz y es puerto muerto donde pueden estar gran cantidad de nauios. (ibidem, f. 4 v.).

${ }^{30}$ Sobre el lugar de la barra de Ayamonte, se indica que, a modo de ejemplo: Y sobre el dicho lugar está vn monte pequeño con tres mogotes pequeños; y quando estos mogotes demoran al nor nordeste, estarán al norte sur con su barra. (ibidem, f. 2 v.). Ejemplos similares se señalan, para ayudar a la orientan, la posición respecto a la Sierra de Cabras en la bahía de Cádiz o toda la sierra en paralelo a la costa al sur del cabo de Trafalgar (ibidem, ff. 3 v., 5 v.).

${ }^{31}$ Es el caso de la salida de la bahía de Cádiz, al sur de la punta de San Sebastián: $Y$ en pasando la baýa de Cádiz hazia el Estrecho, viniendo de mar en fuera y tomares sonda desde las cinquenta brazas hasta las diez brazas, seate auiso que cada diez braças estarás vna legua de tierra o poco más... (ibidem, f. 4 v.).

32 Destaca la gran profusión en la descripción de estas sondas, como se puede ya observar en las notas anteriores. Un ejemplo respecto al grado de detalle y utilidad de estas informaciones de sonda, para la costa entre el cabo de Santa María y la barra de Sanlúcar:

$Y$ si en este camino tomares sonda y hallares en ella arena menuda y blanca, seate aviso que as de estar sobre las Arenas Gordas. Y si la dicha sonda hallares diez braças, estarás vna legua de tierra. Y si boluiendo si bilvuiendo (sic) a sondar en el dicho camino hallares en la sonda arena negra como basa, estarás sobre Carbonero, que es dos leguas de la dicha barra de Sanlúcar y hallarás el propio fondo arriba. Y viniendo por el propio camino y boluieres a sondear y hallares baso suelta y muy 
costa y el sondeo de los fondos, la localización y descripción de las bajas de mayor peligro para la práctica de la navegación de cabotaje y el acceso a los fondeaderos existentes en ella ${ }^{33}$.

Tal reunión de referencias permitía al autor, al fin, ofrecer consejos bien fundados para sortear todos estos riesgos en la singladura junto al litoral y penetrar del modo más seguro en los surgideros y puertos de mayor interés para el tráfico naval de la zona. Buenos ejemplos del modo de proceder del autor los hallamos en las presentaciones que realiza de los accesos a la barra de Sanlúcar, para remontar el Guadalquivir hasta Sevilla, o a la bahía de Cádiz, buscando el gran puerto que representaba Cádiz como escala de primero orden del comercio a larga distancia, a los bajíos de cabo de Trafalgar o a los localizados en torno a Tarifa y la punta del Carnero para enfilar el paso del estrecho de Gibraltar y penetrar en el abrigo ofrecido por la bahía de Algeciras ${ }^{34}$. Considerando globalmente los aspectos citados, el conjunto de la relación ofrece un panorama notablemente sistematizado del estado de los conocimientos náuticos, de base teórica pero también práctica, acumulados por los profesionales de la navegación en el contexto del golfo de Cádiz en el tránsito entre el final de la Edad Media y los albores de la Edad Moderna.

\section{EL CONOCIMIENTO DE LA COSTA. PARA UNA TOPOGRAFÍA DEL LITORAL MERIDIONAL IBÉRICO}

Hemos realizado, pues, una valoración de las fuentes, que permite apreciar su interés y relevancia a la hora de considerar el grado de conocimientos y formación manejado por los marinos locales que surcaban en la época estudiada las costas del sur de la Península Ibérica. En este punto, resulta pertinente abordar en qué medida

blanda y que güele mal, auisate que estarás entonces sobre la propia barra de San Lúcar. Y en toda la distancia d'este camino se ha de hallar casi el propio fondo en quanto a las brazas. (ibidem, ff. 3 v.-4 r.).

Es ya en la Hydrografía de Andrés de Poza (PoçA, Andrés de: Hydrografia..., Libro Segundo, Capítulos I-VI, ff. 2 v.-21 r.) y en los mapas del Spieghel der Zeevaert de Waghenaer, impreso en Leiden entre 1584 y 1585 (manejamos aquí la siguiente edición: WAGHENAER, Lucas Jansz: Pars Prima. Speculum nauticum super navigatione maris Occidentalis confectum..., Leyden, 1588, ff. 18 r.-20v.; http://bdh.bne.es/bnesearch/Search.do?, consultado el 16-V-2013) donde hallamos informaciones de sondas de los fondos marinos del litoral atlántico andaluz y se sitúan con criterio las principales bajas en la entrada al Guadalquivir por la barra de Sanlúcar y en los accesos a la bahía de Cádiz. Estas fuentes, sin embargo, aunque hacen referencia a los brazajes de las sondas, no recogen los tipos de materiales extraídos de los fondos durante el sondeo, al contrario de como ocurre en la relación que aquí tratamos.

${ }_{33}$ Entre las muchas bajas señaladas, puede ser muy ilustrativa la descripción de las que se hallan en el acceso a la barra de Sanlúcar (la roca Salmedina, el Picacho, el Hostial, las Tres Piedras y el Alandar; AGI, Indiferente General, C ${ }^{\mathrm{a}}$. 1.528, n 44 , ff. 3 r.-3v.), las de la bahía de Cádiz (las Puercas, el Diamante y los Frailes; ibidem, f. 4 v.) o las de cabo de Trafalgar, la de Valdevaqueros, próxima a Tarifa,y otra frente a la punta del Carnero en la entrada de la bahía de Algeciras (ibidem, ff. 5 r.-6 r.).

${ }^{34}$ Ibidem, ff. 3r.-4 v., 5 v. La comparación con las referencias ofrecidas en la Hydrografia de Andrés de Poça resultan pertinentes, al observarse divergencias notables. Buen ejemplo lo representan las citas a puertos y accidentes geográficos significativos en ella, que remiten a Ayamonte, San Miguel sobre la barra de Lepe, Lepe, Saltés, Palos, Sanlúcar, Chipiona, Cádiz, cabo Trafalgar, punta de Tarifa y Gibraltar (PoçA, Andrés de: Hydrografia..., Libro Segundo, Capítulos I-VI, ff. 2 v.-3 v., 8 v.-10 r.). 
estas relaciones contribuyen a una reconstrucción de la topografía costera de este espacio entre los siglos XV y XVI.

Para ello, hemos procedido a la identificación de los accidentes geográficos, fondeaderos y puertos recogidos en los tres documentos que hemos presentado y a su representación cartográfica. Con el fin de comparar las informaciones extraídas de estas fuentes, comprender las lógicas a las que pudo obedecer su inclusión en estos documentos y ampliar nuestro grado de conocimientos acerca la geografía portuaria en activo durante la Era de los Descubrimientos en las costas del sur ibérico castellanas y portuguesas, hemos ampliado nuestra pesquisa a las referencias topográficas reunidas en otras fuentes elaboradas en este mismo arco temporal. De este modo, también hemos tenido en cuenta los datos tocantes al litoral meridional ibérico en tres importantes obras impresas de temática náutica muy conocidas. Por un lado, el Grand Routtier..., escrito por el marino gascón Pierre Garcie entre 1483 y 1484, donde, dentro de su descripción de las rutas y derrotas de la costa atlántica europea, se incluyeron algunas informaciones referidas al Algarve y la baja Andalucía $^{35}$. Por otro lado, la Suma de Geographía... del navegante y cartógrafo sevillano Martín Fernández de Enciso, impresa en 1519, donde aparecen, dentro de su descripción geográfica del mundo conocido a principios del siglo XVI, datos relativos a la Península Ibérica y al conjunto de su litoral ${ }^{36}$. Finalmente, la Hydrografía ... del licenciado y cosmógrafo Andrés de Poza de 1585, a la que ya hacíamos referencia por la riqueza de la información náutica que reúne y que también cubría la descripción de las costas ibéricas.

A su vez, la identificación y localización de los hitos costeros considerados en estas fuentes, no siempre sencilla a causa de las transformaciones operadas en los últimos siglos en el relieve físico de algunas zonas del litoral estudiado, en su geografía portuaria y en la misma variación de la toponimia relativa al mismo, se ha apoyado en su contraste a partir de otros dos grandes bloques de fuentes primarias y secundarias. Por una parte, en la bibliografía reciente que se ha ocupado del estudio de las costas atlánticas andaluzas, del reino de Granada en época nazarí y tras la conquista castellana y del reino de Murcia $^{37}$. Por la otra, en recursos cartográficos históricos y actuales que van desde portulanos datados entre el siglo XIV y los comienzos del

${ }^{35}$ Garcie, Pierre, dit Ferrande: Le grand routtier et pylotage et encrage de la mer..., pp. 26-29, 8182.

${ }^{36}$ FeRnÁNDEZ De Enciso, Martín: Suma de Geographia que trata de todas las partidas e provincias del mundo: en especial de las Indias. E trata largamente del arte de marear. Juntamente con la esfera en romance: con el regimiento del sol e del norte, Sevilla, Jacobo Cromberger, 1530 (1'. ed., Sevilla, 1519), ff. XXV v.-XXVII r., XXX v.-XXXI v.

${ }^{37}$ Respecto a los dos primeros espacios, hemos hecho referencia a estos trabajos anteriormente, en particular en las notas 6 a 11. En cuanto al reino de Murcia, vid. Rodríguez Llopis, Miguel: "La integración del reino de Murcia en el comercio europeo al fin de la Edad Media", en CASADo Alonso, Hilario (ed.): Castilla y Europa. Comercio y mercaderes en los siglos XIV, XV y XVI, Burgos, 1995, pp. 81-114; Martínez Martínez, María: "La frontera mediterránea de Castilla: núcleos y actividades en el litoral murciano (ss. XIII-XV)", Murgetana (Murcia) 108 (2003) 43-65; Munuera NaVArro, David: Musulmanes y cristianos en el Mediterráneo. La costa del sureste peninsular durante la Edad Media (ss. VIII-XVI), tesis doctoral defendida en la Universidad de Murcia, Murcia, 2010, pp. 41-74, 169 y ss. 
siglo $\mathrm{XVI}^{38}$ hasta las series históricas de mapas topográficos de España a escalas 1:50.000 y 1:25.000 elaborados desde inicios del siglo XX por el Instituto Geográfico Nacional ${ }^{39} \mathrm{o}$ las herramientas ofrecidas por la aplicación informática Google Earth ${ }^{\mathrm{TM}}$, pasando por otras evidencias cartográficas de los siglos XVI-XVIII ${ }^{40}$.

El resultado de este esfuerzo puede observarse en las tablas 1 a 6 y los correspondientes mapas 1 y 2 . En éstos, para facilitar el análisis comparativo de la información, obedeciendo a las características formales, la cantidad y la calidad de las referencias recogidas en cada una de las seis fuentes manejadas, se ha procedido a su agrupación, representándose, por un lado, los datos obtenidos del Grand routtier, la Suma de Geographía, la Memoria... de 1526 y la Relaçión... posterior a 1554, y, por el otro los procedentes de la Relación ... posterior a 1555 y la Hydrografia... de 1585. El criterio cronológico también ha jugado un papel en esta selección, en la medida en que el primer mapa sí se refiere a un horizonte de conocimientos bien delimitado entre finales del siglo XV y mediados del siglo XVI. Mientras, para el segundo de ellos, se ha pretendido establecer un contraste entre los datos ofrecidos por la Relación..., que procede a una descripción verdaderamente exhaustiva de la costa y los fondos del área del golfo de Cádiz, en las décadas centrales del siglo XVI, y los que ya aparecen en el tratado de Andrés de Poza, a finales del siglo XVI, cuando

${ }^{38}$ Hemos manejado para ello el corpus de reproducciones en formato digital de cartas náuticas y atlas reunido en dos obras. Por una parte, las recogidas en la magna obra de PUJAdEs i BATALLer, Ramon J.: Les Cartes portolanes. La representació medieval d'una mar solcada, Barcelona, Institut d'Estudis Catalans-Institut Cartogràific de Catalunya-Institut Europeu de la Mediterrània-Lunwerg, 2007, 528 págs. +1 DVD. Por otra parte, las publicadas por el Museo de Historia de Tenerife en formato CDROM con el título Portulanos del Mundo. Desde la Antigüedad al siglo XV en el marco de un proyecto desarrollado entre los años 1995 y 2000. El primero de estos trabajos reúne imágenes de hasta 129 cartas y atlas datados entre el final del siglo XIII y 1470. Mientras, el segundo recoge un total de 92 de estos documentos en una cronología que algo más amplia que va de finales del siglo XIII a los inicios del siglo XVI, aunque muchos de ellos compilados por PUJADEs i Bataller en imágenes de mayor calidad, resultando por ello de particular interés los fechados con posterioridad a 1470.

${ }^{39}$ El conjunto de esta información cartográfica es propiedad del @ Instituto Geográfico Nacional de España. Puede accederse a ella a de la dirección web: http://centrodedescargas.cnig.es/CentroDescargas/ index.jsp.

${ }^{40}$ Hemos considerado para ello los mapas y dibujos que aparecen en obras célebres como los de Joris Hoefnagel para el Civitates Orbis Terrarum [Braun, Georg, Hogenberg, Franz (Füssel, Stephan: ed.): Cities of the World. Complete Edition of the Colour Plates of 1572-1617, Colonia, 2008], los recogidos en el Teatrum Orbis Terrarum de Abraham Ortelius, impreso en Amberes en 1570 (http://memory.loc. gov/ammem/gmdhtml/gnrlort.html; consultado el 16-V-2013), en el Spieghel der zeevaerdt (vid. nota 32) o en los elaborados para La descripción de España y de las costas y puertos de sus reinos de 1634 de Pedro Teixeira [Pereda, Felipe, Marías, Fernando (eds.): El Atlas del Rey Planeta. «La descripción de España y de las costas y puertos de sus reinos», de Pedro Texeira (1634), Fuenterrabía, Nerea, 2002, 398 págs.]. Igualmente, son de interés los dibujos dedicados a distintas ciudades y ámbitos costeros andaluces por el pintor flamenco Antón Van den Wyngaerde entre 1561 y 1570 [KAGAN, Richard L. (dir.): Ciudades del Siglo de Oro: las vistas españolas de Anton Van der Wyngaerde, El Viso, Madrid, El Viso, 1986, 432 págs.]. Finalmente, se han tenido en cuenta los fondos cartográficos de distintos archivos y bibliotecas españolas, con particular atención a la sección de Mapas, Planos y Dibujos del AGS. 
la difusión de este tipo de informaciones comienza a generalizarse en obras diversas de temática geográfica y náutica ${ }^{41}$.

El resultado conjunto permite disponer de una imagen notablemente completa del estado de reconocimiento de las costas meridionales de la Península Ibérica que, entre finales del siglo XV y los años centrales del siglo XVI, podía ser manejado por los marinos veteranos en estas aguas, de los puntos de referencia tenidos en cuenta en la navegación de cabotaje por este litoral y de la propia evolución de esta apreciación del espacio y de su puesta en común en forma de conocimiento letrado. Sólo el área de la costa mediterránea entre Gibraltar y La Herradura (Almuñécar) aparece reconocida de forma menos intensiva.

Tabla 1. Pierre Garcie, Dit Ferrande, Grand routtier et pylotage et encrage de la mer..., $1483-1484$

\begin{tabular}{|l|l|}
\hline LUGARES Y ACCIDENTES RECOGIDOS EN EL TEXTO & \multicolumn{1}{c|}{ CORRESPONDENCIAS ACTUALES } \\
\hline Cap de Sainct Vincent & Cabo de San Vicente \\
\hline Cap de Saincte Marie & Cabo de Santa María \\
\hline Baye Dolues & Bahía de Huelva \\
\hline Ponteau de Ferron & ¿Faro? \\
\hline Sainct Lucas de Baramedo & Sanlúcar de Barrameda \\
\hline Lisle de Calix & Isla de León; Cádiz \\
\hline Treflagar & Trafalgar \\
\hline Lestroict de Marroc & Estrecho de Gibraltar \\
\hline Cap de Gatte & Cabo de Gata \\
\hline Les Formyngues & Islas Hormigas, frente al cabo de Palos \\
\hline & \\
\hline
\end{tabular}

${ }^{41}$ No deja de ser representativo de este salto cualitativo en la sistematización de estos conocimientos que, en el Livro de Marinharia de João de Lisboa, compilación de en torno a 1560 aunque reúne materiales datados al menos desde 1514 [LisboA, João de (ReBello, Jacinto Ignacio de Brito, ed.): Livro de Marinharia: tratado da agulha de marear de João de Lisboa: roteiros, sondas e outros conhecimentos relativos à navegação, Lisboa, Imprensa de Libanio da Silva, 1903, 308 págs; acceso al manuscrito original en http://digitarq.dgarq.gov.pt/details?id=4162625; consultado el 25-V-2013], por más que aparecen datos de gran interés acerca de las rutas, leguas y travesías para las costas del sur ibérico, no se haga mención a los sondeos de las mismas, no obstante éstos sí son referidos para las los litorales de Francia, Flandes y las islas Británicas. Hay que esperar a encontrar estos datos en la tratadística náutica a la década de 1580, en el Spieghel der Zeevaerdt o en la obra de Poza (vid. nota 32). 
Tabla2. Martín Fernández De Enciso, Suma De Geographia..., 1519

\begin{tabular}{|l|l|}
\hline \multicolumn{1}{|c|}{$\begin{array}{c}\text { LUGARES Y ACCIDENTES } \\
\text { RECOGIDOS EN EL TEXTO }\end{array}$} & \multicolumn{1}{c|}{ INFORMACIÓN NÁUTICAS COMPLEMENTARIAS } \\
\hline Cabo de San Vicente & Junto al cabo, al este. Buen puerto. \\
\hline Lagos & $\begin{array}{l}\text { Entrada del río Guadiana. } \\
\text { Divisoria entre Portugal y Castilla. }\end{array}$ \\
\hline Bahía de Lepe & Están los tres en la bahía de Lepe. \\
\hline $\begin{array}{l}\text { Tavira } \\
\text { Saltés }\end{array}$ & $\begin{array}{l}\text { Entrada del río Guadalquivir. } \\
\text { Breve descripción de la desembocadura. }\end{array}$ \\
\hline Sanlúcar de Barrameda & $\begin{array}{l}\text { Remontando el río. } \\
\text { Se destaca su población y su comercio a causa de su puerto. }\end{array}$ \\
\hline Sevilla & $\begin{array}{l}\text { Isla pequeña. } \\
\text { Valoración de su bahía como buen puerto y una de las } \\
\text { mayores escalas de la Cristiandad. }\end{array}$ \\
\hline Cádiz & $\begin{array}{l}\text { Dentro de la bahía. Bueno puerto. } \\
\text { Entrada del río Guadalete. }\end{array}$ \\
\hline El Puerto de Santa María & En el estrecho de Gibraltar. \\
\hline Tarifa & Distancia entre África y Europa en el Estrecho. \\
\hline Gibraltar & Puerto. \\
\hline Marbella & Mayor ciudad y puerto del reino de Granada. \\
\hline Málaga & Puerto y gentil lugar junto al cabo de Gata. \\
\hline Almería & El mejor puerto de España del Mediterráneo. \\
\hline Cabo de Gata & \\
\hline Cartagena & \\
\hline Cabo de Palos & \\
\hline
\end{tabular}

Tabla 3. Memoria de los puertos y calas que hay desde el Cabo de Palos hasta la punta del Carnero..., fin. 1526

(AGS, Cámara de Castilla. Diversos, C $.44, n^{\circ} .15$ )

\begin{tabular}{|l|l|}
\hline LugARES Y ACCIDENTES RECOGIDOS EN EL TEXTO & \multicolumn{1}{c|}{ CORRESPONDENCIAS ACTUALES } \\
\hline Cabo de Palos & Cabo de Palos \\
\hline Pormín & Portmán \\
\hline El Gorger & El Gorguer \\
\hline Tarfajuror & ¿Trapajuar? \\
\hline Escombrera & Escombreras \\
\hline Cartajena & Cartagena \\
\hline Rotliz & ¿El Portús? \\
\hline La Yngalada & ¿Cala Aguilar? \\
\hline L'Azubia & La Azohía \\
\hline
\end{tabular}




\begin{tabular}{|l|l|}
\hline Maçarrón & Puerto de Mazarrón \\
\hline La ysla de Maçarrón & La isla \\
\hline La cala del Adelantado & Desconocida ${ }^{44}$ \\
\hline El Copo & Cabo Cope \\
\hline Cala Verdina & Calabardina \\
\hline Las Ágilas & Águilas \\
\hline Cala Rredeña & Calarreona \\
\hline Los Terreros Blancos & San Juan de los Terreros \\
\hline La Mesa de Roldán & La Mesa de Roldán \\
\hline La cala del Plomo & La cala del Plomo \\
\hline San Pedro el Arráiz & Cala de San Pedro \\
\hline Puerto Ginoveses & Puerto Genovés \\
\hline La Vela Blanca & Acantilado y torre de la Vela Blanca \\
\hline El cabo de Gata & Cabo de Gata \\
\hline Almería & Almería \\
\hline Las Roquetas & Roquetas de Mar \\
\hline Las Albuferas & Punta Entinas \\
\hline Guarda Vieja & Guardias Viejas \\
\hline Castil de Ferro & Castell de Ferro \\
\hline El Arrayhana, junto a Castil de Ferro & Cala Rijana \\
\hline La cala del Arena & Calahonda \\
\hline Salobreña... que abriga Trafalcaçiz & Salobreña \\
\hline Velilla & Velilla \\
\hline Los Berengeles & Los Berengueles \\
\hline La Herradura & La Herradura \\
\hline Málaga & Málaga \\
\hline Gibraltar & Gibraltar \\
\hline La punta del Carnero & Punta del Carnero \\
\hline & \\
\hline
\end{tabular}

${ }^{42}$ La identificación que hemos realizado se basa en la cercanía fonética entre el término del documento y el de Tarfajuror, paraje en la costa entre El Gorguer y Escombreras. Sin embargo, esta localización no deja de ser hipotética, al no encontrarse referencia que permita un mejor reconocimiento topográfico sobre mapa o fotografía satélite.

${ }^{43}$ No hemos logrado hallar la correspondencia de estos topónimos pero se refieren a alguna de las calas y playas situadas entre la playa de El Portús y el entorno de cabo Tiñoso. Por mapa de 1762 (AGS, Mapas, Planos y Dibujos, 46, 14), a partir de la identificación de la cala del Bolete, se pueden reconocer La Yngalada como la ahí señalada con nombre de Cala Angular, hoy Cala Aguilar, y, a su vez, Rotliz probablemente con la actual playa de El Portús.

${ }^{44}$ Se trata de una de las calas situadas al este de Mazarrón, sin poder precisarse cuál de ellas.

${ }^{45} \mathrm{Se}$ desconoce el emplazamiento concreto de este lugar, que no obstante ha de situarse en el área de la playa de los Genoveses, dentro del Parque Natural del Cabo de Gata.

${ }^{46} \mathrm{Al}$ aparecer citado previamente que Guarda Vieja y en la misma distancia que este lugar respecto de Almería, parece aconsejable no identificarlo con las albuferas de Adra sino, más bien, con la zona de lagunas en torno a Punta Entinas y la ensenada de San Miguel, en el municipio de El Ejido, muy próxima a Guardias Viejas. 
Tabla 4. Relaçión de los puertos y cauos dela costa de España..., posterior a 1554

(AGI, Indiferente General, $C^{\mathrm{a}} .1 .528, \mathrm{n}^{\circ} 39$ )

\begin{tabular}{|l|l|}
\hline LugARES Y ACCIDENTES RECOGIDOS EN EL TEXTO & \multicolumn{1}{c|}{ CoRRESPONDENCIAS ACTUALES } \\
\hline Cauo de San Vicente & Cabo de San Vicente \\
\hline Cauo de Santamarýa & Cabo de Santa María \\
\hline Cavo de Sanlúcar de Barrameda & ¿Punta de Chipiona? \\
\hline Cádiz & Cádiz \\
\hline Estrecho de Gibraltar & Estrecho de Gibraltar \\
\hline Gibraltar & Gibraltar \\
\hline Marbella & Marbella \\
\hline Funjirola & Fuengirola \\
\hline Málaga & Málaga \\
\hline Vélez Málaga & Torredelmar, Vélez-Málaga \\
\hline La Herradura y Almería & La Herradura y Almería \\
\hline Cauo de Gata y Lunbreras Viejas & Cabo de Gata y ¿Puerto de Mazarrón, \\
Mazarrón?
\end{tabular}

${ }^{47}$ Este punto es citado de manera errónea, después del cabo de Palos y antes que las islas Hormigas y Alicante (f. 1 v.). Puesto que el autor de la relación declaraba no usar cartas de marear ni libros de derrota para apoyar su elaboración, todo parece indicar que nos encontramos ante una muestra de que la experiencia náutica que este personaje tenía en el cabotaje del litoral mediterráneo hispano debía de ser limitada.

${ }^{48}$ Aunque con la denominación de Lumbreras o Alumbres Viejos se identificó habitualmente a Mazarrón, también se tiene noticia de la referencia, en documentación del siglo XVI relacionada con el corso berberisco, de una cala de los Alumbres Viejos en el entorno del cabo de Gata-cuya localización exacta no hemos podido precisar- que también podría responder a la cita en la relación aquí estudiada (TAPIa Garrido, José Ángel: "La costa de los piratas", Revista de Historia Militar (Madrid) 32 (1972) 73-104/74, 86-89). 
Tabla 5. Relación de los puertos y barras que hay en la costa desde el cabo de San Vicente hasta el cabo de Trafalgar, posterior a 1555

(AGI, Indiferente General, $\mathrm{C}^{\mathrm{a}}$. 1.528, $\mathrm{n}^{\mathrm{o}} 44$ )

\begin{tabular}{|l|l|}
\hline $\begin{array}{l}\text { LugARES Y ACCIDENTES RECOGIDOS EN } \\
\text { EL TEXTo }\end{array}$ & \multicolumn{1}{c|}{ CoRRESPONDENCIAS ACTUALES } \\
\hline Cabo de San Vicente & \\
\hline Puerto de Sagres & Baleeira, que cierra la bahía de Sagres. \\
\hline La Baliera & \\
\hline Bahía de Lagos & Barra de Vila Nova de Portimão. \\
\hline Barra de Villanueva & \\
\hline Cabo de Santa María & \\
\hline Barra de Faro & Barra de Tavira. \\
\hline Barra de Tabira & \\
\hline Barra de Ayamonte & Barra de Huelva, o de Isla Saltés. \\
\hline Barra de Guelba & \\
\hline Arenas Gordas & \\
\hline Barra de Sanlícar de Barrameda & Baja semiemergida frente a Chipiona. \\
\hline Salmedina & \\
\hline Bahia de Cádiz & Ermita de Santa Catalina, La Caleta, isla de León, \\
\hline Canta Catalina & Cád ermita y punta de Santa Catalina, El \\
\hline El Puntal & Punta al noreste de la isla de León, Cádiz. \\
\hline San Sebastián & Islote y ermita a poniente de la isla de León, Cádiz \\
\hline Santi Petro & Sancti Petri \\
\hline Cabo de Roch & Cabo Roche \\
\hline Playa de Conil & \\
\hline Cabo de Trafalgar & \\
\hline Barra de Barbate & \\
\hline Almadraba de Zahara & Zahara de los Atunes \\
\hline Baja de Valdevaqueros & \\
\hline Villa de Tarifa & \\
\hline Isla de Tarifa & \\
\hline Punta del Carnero & \\
\hline Bahía de Gibraltar & \\
\hline & \\
\hline
\end{tabular}

${ }^{49} \mathrm{La}$ consulta de las fuentes no es del todo concluyente, pudiendo referirse tanto a la ermita que se hallaba a poniente de La Caleta de Cádiz, delimitando esta playa, como a otra ermita de la misma advocación próxima a El Puerto de Santa María y que se situaba sobre una punta en la zona norte de la entrada a la bahía de Cádiz. Al abrigo de esta punta también existen pequeñas playas. Tanto una como otra localización aparecen en los planos y dibujos del siglo XVI sin que podamos establecer mayor precisión sobre una u otra, si bien el orden de la descripción de la costa por la isla de León invita a pensar que mejor se esté refiriendo a la primera de ambas opciones. 
Tabla 6. Andrés de Poza, Hydrografia..., 1585

\begin{tabular}{|c|c|}
\hline $\begin{array}{c}\text { LUGARES Y ACCIDENTES RECOGIDOS EN } \\
\text { EL TEXTO } \\
\end{array}$ & CORRESPONDENCIAS ACTUALES \\
\hline \multicolumn{2}{|l|}{ Cabo de San Vicente } \\
\hline \multicolumn{2}{|l|}{ Lagos } \\
\hline Albor & Alvor \\
\hline Villanueva; Silves; foz de Silves & $\begin{array}{l}\text { La barra, abra, foz, que da acceso a Vila Nova de } \\
\text { Portimão y Silves. }\end{array}$ \\
\hline Albufera & Albufeira \\
\hline \multicolumn{2}{|l|}{ Cabo de Santa María } \\
\hline \multicolumn{2}{|l|}{ Faro; abra de Faro; la foz } \\
\hline \multicolumn{2}{|l|}{ Tavira } \\
\hline \multicolumn{2}{|l|}{ Ayamonte; abra de Guadiana } \\
\hline \multicolumn{2}{|l|}{$\begin{array}{l}\text { Lepe; abra de San Miguel sobre la } \\
\text { barra de Lepe }\end{array}$} \\
\hline Palos; Saltés; abra de Saltés & Abra de la ría de Huelva. \\
\hline Sanlúcar; Barrameda & Sanlúcar y la barra de Sanlúcar \\
\hline Salmedina & Baja semiemergida frente a Chipiona. \\
\hline \multicolumn{2}{|l|}{ Chipiona } \\
\hline Corrales de Rota & Corrales de pesca al noroeste de Rota \\
\hline \multicolumn{2}{|l|}{ Cádiz; bahía de Cádiz } \\
\hline Santa Catalina & $\begin{array}{l}\text { Ermita de Santa Catalina, La Caleta, isla de } \\
\text { León, Cádiz // ermita y punta de Santa Catalina, } \\
\text { El Puerto de Santa María }^{50}\end{array}$ \\
\hline San Sebastián de Cádiz & Punta al norte de la isla de Cádiz \\
\hline \multicolumn{2}{|l|}{ Conil } \\
\hline \multicolumn{2}{|l|}{ Cabo de Trafalgar } \\
\hline $\begin{array}{l}\text { Punta del Ciervo; Peña del Ciervo; } \\
\text { baja al través de }\end{array}$ & Baja de Valdevaqueros \\
\hline \multicolumn{2}{|l|}{ Tarifa } \\
\hline \multicolumn{2}{|l|}{ Isla de Tarifa } \\
\hline Puntal del Carnero & Punta del Carnero \\
\hline \multicolumn{2}{|l|}{ Gibraltar; monte de Gibraltar } \\
\hline Molinos D’em-gala; Cabo de Málaga & Torremolinos; ¿Punta del Saltillo, Torremolinos? \\
\hline Salobrina & Salobreña \\
\hline Llana de Almería & Guardias Viejas-Punta Entinas ${ }^{51}$ \\
\hline \multicolumn{2}{|l|}{ Cabo de Gata } \\
\hline \multicolumn{2}{|l|}{ Cabo de Palos } \\
\hline Las Hormigas & Islas Hormigas, frente al cabo de Palos \\
\hline
\end{tabular}

${ }^{50}$ En este documento tampoco se precisa en modo alguno a cuál de las dos localizaciones se refiere concretamente.

${ }^{51}$ Los portulanos anteriores a mediados del siglo XVI en ocasiones recogen el topónimo de Lena D'almeria u otras variantes, que autores como Gozalbes Cravioto o González Arévalo identifica con la 


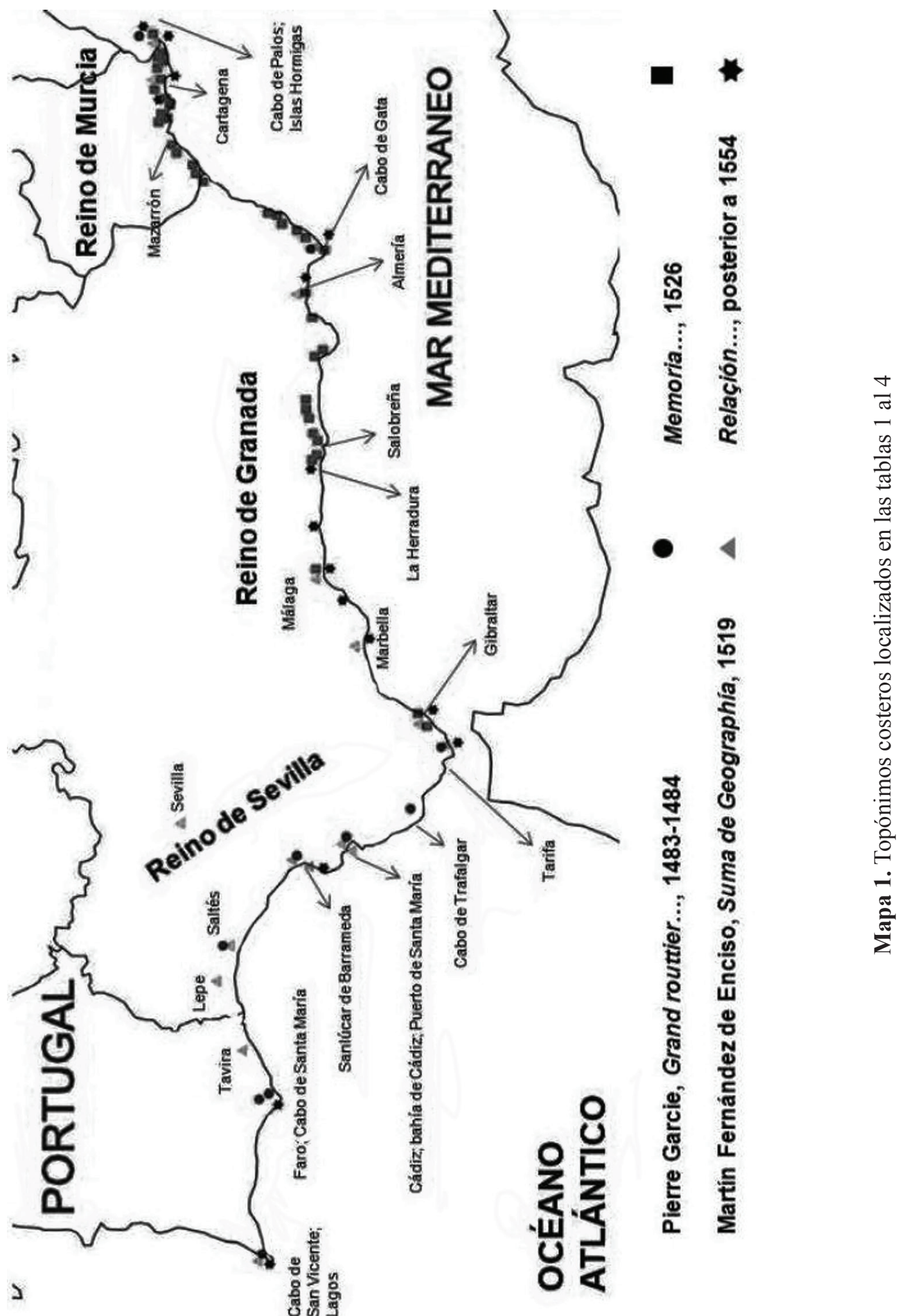




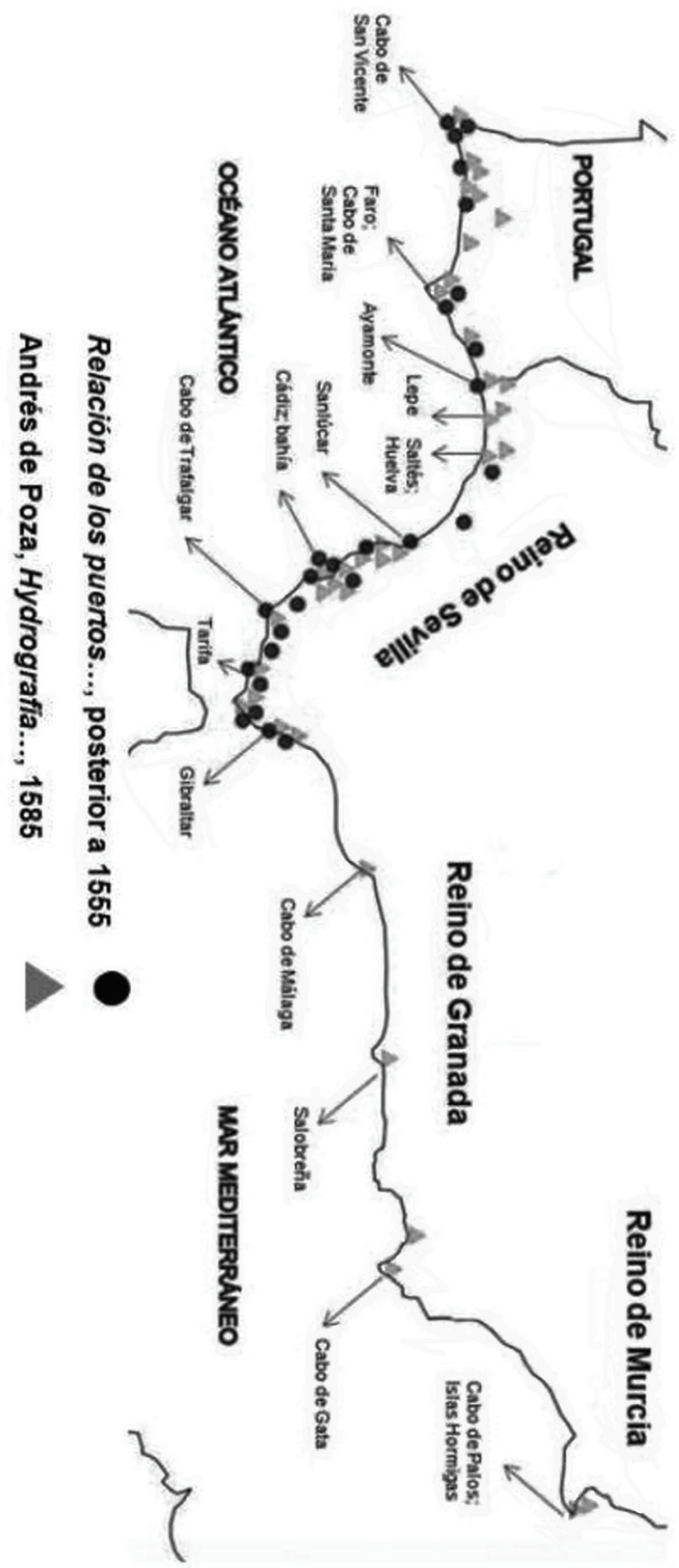


A partir de los datos expuestos acerca de esta topografía náutica del litoral meridional ibérico entre el final de la Edad Media y el inicio de la Edad Moderna, cabe poner de manifiesto algunas impresiones que pueden extraerse de su análisis.

De este modo, resulta sumamente significativo el carácter eminentemente geográfico de la toponimia extraída a partir de las fuentes manejadas. Si la lógica subyacente en la elaboración de esta documentación náutica tenía que ver con la consignación de cuantas referencias fueran de necesario conocimiento para el desarrollo de la navegación por las costas tratadas de manera segura y eficiente (distancias, rumbos, direcciones de los vientos y travesías, señales para la orientación respecto a la costa, sondas, etc.), es muy llamativo que la mayoría de las referencias aportadas sirvan para denominar accidentes geográficos de toda consideración: cabos, puntas, islas, barras, abras, bajas, calas, etc. Mientras, la cita de lugares portuarios resulta mucho menos numerosa y, en buena medida, ligada de manera subsidiaria a la referencia de algún accidente geográfico físico.

Es más, en las ocasiones en que hallamos topónimos referidos a toda suerte de puertos y fondeaderos, tanto en los casos en que pueden asociarse a núcleos poblados -como ocurre con, por ejemplo, con Lepe, Sanlúcar de Barrameda, Cádiz, Tarifa, Málaga, Almería, Mazarrón o Cartagena, por limitarnos al territorio de la Corona de Castilla y el reino de Granada- como en los que no estaban vinculados de forma directa a una población - casos de las múltiples calas, cabos y playas recogidos en la Memoria ... de 1526, por ejemplo en el entorno del cabo de Gata-, tales lugares señalados con valor portuario son reconocibles habitualmente por la aptitud orográfica natural de los mismos para acoger el acceso y fondeo de navíos. Abundando en esta misma idea, no hallamos en ninguna de las relaciones ni tampoco en los tres tratados impresos que hemos manejado para estos puertos y surgideros referencia alguna a la existencia en ellos de posibles infraestructuras artificiales, fruto de la acción humana, destinadas a optimizar su aprovechamiento con fines navales. Todo ello, en fin, nos conduce a pensar que la presencia de lugares portuarios en estos documentos náuticos sólo era un elemento más entre todos los que se entendían que habían de ser tenidos en cuenta por parte de los marinos de la época para asegurar el buen transcurso de la singladura por estas zonas costeras.

Así pues, la atención de los navegantes, según estos textos, se dirigía hacia cuestiones ligadas al reconocimiento de señales en la costa útiles para su orientación desde el mar, de peligros para la integridad de las embarcaciones en las maniobras que

zona de la desembocadura del río de Adra y el campo de Dalias [Gozalbes Cravioto, C: "La frontera oriental nazarí en los portulanos medievales", en Segura Artero, P. (ed.): Actas del Congreso La Frontera Oriental Nazarí..., pp. 451-466, en concreto p. 454; GonzÁlez ArÉVAlo, R: "La costa del Reino de Granada..., p. 20; Malpica Cuello, A, FÁbregas García, A: "Embarcaderos y puertos...”, p. 78]. A partir de cartas como las del Atlas de Juan Ortiz Valero, de 1575 (Centro Geográfico del Ejército, Atlas 1) o un mapa que cubre la costa entre Adra y Almería del siglo XVIII (AGM, Cartoteca, AL-03-16), puede apreciarse que con el nombre de llana o llanos de Almería se denominaba el espacio del campo de Dalias. Aunque pudo estar en activo con anterioridad ya al siglo XII con el nombre de al-Nubaira, la pervivencia del topónimo cristiano posterior en el siglo XVI, su aparición como un hito náutico en esta relación y las referencias recogidas en la Memoria ... de 1526 nos lleva a identificarlo, para esta época del final de la Edad Media y los inicios de la Edad Moderna, preferentemente con alguna de estas dos puntas situadas al sur del mismo, esto es, Punta Entinas o la de Guardias Viejas. 
se emprendieran durante el cabotaje, de espacios aptos para refugiar y aprovisionar los barcos durante la ruta y de entradas apropiadas a ensenadas, bahías y cursos fluviales que dieran acceso a fondeaderos y puertos que fueran escala o destino de sus viajes. En este sentido, y pese a lo señalado anteriormente, la toponimia fundamentalmente geográfica recogida en estas relaciones y tratados náuticos sí contribuye a ofrecer al investigador una imagen bien aproximada de tales entradas, surgideros y escalas más practicados por la navegación en toda la zona del sur de la Península Ibérica entre, al menos, finales del siglo XV y mediados del siglo XVI.

Ahora bien, a la hora de aproximarnos a una posible jerarquía portuaria entre los espacios recogidos por esta documentación, las evidencias que manejamos no terminan de ser concluyentes, precisamente por el carácter fundamentalmente geográfico e hidrográfico de las informaciones recogidas en los textos. Es cierto que gracias a estas relaciones tenemos constancia de que la actividad naval en una multitud de barras, rías, ensenadas, playas, surgideros y puertos por toda esta costa era comúnmente conocida y considerada entre la marinería de la época. Sin embargo, a la hora de valorar cuáles de estos lugares portuarios podían ser de mayor importancia frente a otros, las evidencias en estas fuentes no dejan de tener un reducido valor cualitativo. Las contribuciones en esta línea pueden limitarse a las contadas referencias calificativas que Martín Fernández de Enciso realizó en su descripción geográfica de la Península Ibérica o a la propia jerarquía interna que se establece entre los puntos en el litoral de los reinos de Granada y de Murcia señalada en el orden interno de la Memoria ... de 1526. Estos datos y la citación reiterada de algunos de los lugares costeros aparecidos a lo largo de los distintos documentos y tratados estudiados permiten apuntar algunas ideas respecto a las jerarquías portuarias en la Corona de Castilla y el reino de Granada en torno al 1500, por otra parte, de escasa profundidad y coincidentes con el bagaje historiográfico con el que contábamos a este respecto ${ }^{52}$. Por un lado, el peso del complejo Sanlúcar-Sevilla, en torno el acceso al Guadalquivir hasta la gran urbe hispalense, y de Cádiz y su bahía, en el área atlántica andaluza. Por otra parte, para el ámbito mediterráneo, la preeminencia de Málaga, Almería y Cartagena en el Mediterráneo.

Con todo, tampoco puede dejar de atenderse que sólo el espacio navegable más inmediato a la costa y los accesos a cursos fluviales a través de rías desde el mar fueron objeto de atención en las fuentes náuticas manejadas. A cuenta de ello, dentro de la citación de lugares portuarios en el ámbito atlántico andaluz se detectan algunas ausencias de consideración cuando, historiográficamente, es conocida la influencia de las actividades ligadas al mar en esos núcleos no referidos durante los siglos XV y XVI. Esto da lugar que el mismo gran puerto de Sevilla no sea citado en ninguna de las relaciones ni en los otros dos textos de contenido más eminentemente náutico, apareciendo sólo en la descripción geográfica de Enciso. En este mismo sentido, aunque hay lugar a reconocer los puertos del Algarve, en el reino de Portugal, y los de la tierra llana de Huelva y el condado de Niebla y todos aquéllos situados entre Cádiz

52 Ya hemos hecho mención a un buen número de trabajos acerca del desarrollo portuario en los territorios castellanos del reino de Sevilla y el reino de Murcia y en el reino de Granada antes y después de la conquista cristiana en las notas $3,6-11$ y 37 . 
y Gibraltar ${ }^{53}$, tampoco se notifica nada acerca de los puertos del interior de la bahía de Cádiz fuera de los propios surgideros en torno a la isla de León y la ciudad de Cádiz. Es un importante vacío que afecta a lugares que nos consta que tuvieron una notable dinámica naval, fundamentalmente ligada al tráfico comercial pero también a actividades militares, como El Puerto de Santa María, el puerto fluvial sobre el río Guadalete de Jerez de la Frontera en El Portal y la villa de Puerto Real fundada en 1483 por la Corona como base centralizadora de la organización de cabalgadas contra Berbería ${ }^{54}$. Estas ausencias, en cualquier caso, nos ponen al corriente de que los conocimientos acerca de la navegación por este tipo de aguas interiores y cursos fluviales quedaban al margen del cúmulo de saberes náuticos que estaba entrando en circulación en el ambiente de cosmógrafos, pilotos y otros marinos hispanos empeñados en las principales rutas marinas que intercomunicaban los ámbitos mediterráneo y atlántico del Viejo Mundo y los nuevos espacios de descubrimiento y colonización hacia África y, desde el final del siglo XV, hacia el Índico, Asia y América ${ }^{55}$.

\section{CONCLUSIÓN}

La elaboración y conservación de las tres relaciones relativas a las costas ibéricas -fundamentalmente a las andaluzas- que hemos tenido la ocasión de estudiar sin duda fue ajena a los procedimientos y canales de circulación de la información de temática náutica convencionales en el tránsito entre el Medievo y la Modernidad.

53 Vid. notas 3 y 11.

54 Vid. GonzÁlez Jiménez, M.: "La baja Andalucía...”; LAdero Quesada, M. Á.: Andalucía en torno a 1492. Estructuras. Valores. Sucesos, Madrid, Editorial Mapfre, 1992, 343 págs.; AzNAR Vallejo, E.: "La guerra de allende. Condicionantes mentales y técnicos de la nuevas frontera", en XXXI Semana de Estudios Medievales. Estella, 19 al 23 de julio de 2004. Guerra y Diplomacia en la Europa Occidental, 1280-1480, Pamplona, 2005, pp. 83-115; Collantes de Terán SÁnchez, A.: "Papel del Atlántico...". Más en concreto, entre otros títulos posibles, sobre El Puerto de Santa María, VV. AA.: El Puerto de Santa María entre los siglos XIII y XVI. Estudios en homenaje a Hipólito Sancho de Sopranis en el centenario de su nacimiento, El Puerto de Santa María, Ayuntamiento de El Puerto de Santa María, 1993, 125 págs.; Iglesias Rodríguez, Juan José: Monarquía y nobleza señorial en Andalucía. Estudios sobre el señorio de El Puerto (siglos XIII-XVIII), Sevilla, Universidad de Sevilla, 2003, 166 págs. Sobre Jerez de la Frontera, SAncho de Sopranis, Hipólito: Historia social de Jerez de la Frontera al fin de la Edad Media, 3 Vols., Jerez de la Frontera, Centro deEstudios Históricos Jerezanos 1959; MarTín GutiérRez, Emilio: La identidad rural de Jerez de la Frontera. Territorio y poblamiento durante la Baja Edad Media, Cádiz, Universidad de Cádiz, 2003, 192 págs.; IDEM, "La participación de Jerez de la Frontera en los circuitos comerciales atlánticos a finales de la Edad Media: los contratos de fletamento", en GonzÁLEZ Jiménez, M., Montes Romero-CAmacho, Isabel (eds.): La Península Ibérica entre el Mediterráneo y el Atlántico. Siglos XIII-XV, 2006, Cádiz, pp. 133-141. En cuanto a Puerto Real, Iglesias Rodríguez, J. J.: La villa de Puerto Real en la Edad Moderna, 1483-1812, Sevilla, 2002, 145 págs.

${ }^{55}$ En torno a este contexto y la participación de marinos castellanos en estos fenómenos, vid. AzNAR VAlLejo, E.: "La experiencia marítima: las rutas y los hombres del mar", Andalucía 1492, razones de un protagonismo, Sevilla, 1992, pp. 125-156; IDEM: "Los itinerarios atlánticos en la vertebración del espacio hispánico. De los Algarbes al Ultramar Oceánico", en XXVII Semana de Estudios Medievales. Estella. 17 al 21 de julio de 2000. Itinerarios medievales e identidad hispánica, Pamplona, 2001, pp. 47-82. 
Afortunadamente, su puesta por escrito y preservación en el marco de un contexto de desarrollo de los poderes monárquicos en la Corona de Castilla y de integración de las cuestiones de orden naval como un asunto a tener en cuenta para la defensa de los intereses estratégicos militares y económico-comerciales de la Monarquía Española por parte de los agentes activos en la gestión del poder monárquico, nos ha dotado de una extraordinaria oportunidad para profundizar en el campo del saber náutico hispano de finales del siglo XV y mediados del siglo XVI. A lo largo de estas páginas, gracias al acceso a esta documentación inédita y a su análisis comparado a partir de un amplio corpus de fuentes doctrinales y cartográficas de la época, hemos establecido una aproximación de interés, a nuestro juicio, a ese horizonte de conocimientos náuticos en relación con la percepción del espacio manejado en los ambientes marineros de las costas meridionales ibéricas entre el final de la Edad Media y los inicios de la Edad Moderna.

Así, de una parte, hemos podido constatar que el valor fundamental de las relaciones náuticas inéditas a las que hemos accedido radica en su capacidad para ponernos en situación sobre el grado de conocimientos teóricos y prácticos atesorados por las gentes del mar de la Castilla meridional, tanto en su ámbito mediterráneo como en el Atlántico. En este sentido, los documentos manejados se manifiestan como testimonios excepcionales acerca de la aplicación de aspectos técnicos y de enseñanzas empíricas que tocan a cuestiones como el cálculo de la posición de los navíos en el mar, de las distancias y los rumbos, de las direcciones de los vientos y travesías, etc., Pero también del mismo conocimiento del espacio físico del litoral de los reinos de Sevilla, de Granada y de Murcia, desde su aprehensión mental por parte de estos profesionales del mar al manejo de multitud de datos acerca de la accesibilidad para la navegación de la costa, de sus accidentes geográficos y de sus puertos y surgideros.

A cuenta de lo observado en estas páginas, los documentos manejados permiten apreciar, a partir del contrastes en las referencias náuticas más técnicas y del grado de precisión en la descripción hidrográfica de los relieves costeros, evidencias de tradiciones locales en la práctica de la navegación a corta distancia diferenciadas para los ámbitos atlántico y mediterráneo del sur peninsular y que a principios del siglo XVI aún se manifestaban. Pero, de la misma manera, también hemos podido acceder a las dinámicas de incrementación y compilación de conocimientos navales en el tránsito entre la Edad Media y la Edad Moderna en todo este ámbito andaluz y, en general, meridional castellano y aun si cabe más importante, de sistematización y difusión por vía escrita e impresa de estos conocimientos, enmarcados en las grandes rutas marinas abiertas entre el Mediterráneo y el Atlántico y hacia África y las Indias. Unos saberes que originalmente sólo habrían circulado en una escala menor, dentro de círculos socio-profesionales y espaciales muy restringidos para posteriormente dar el salto a la amplia difusión gracias a la letra impresa al menos a partir de mediados del siglo XVI. Una difusión de conocimientos naúticos que fue más temprana por lo que se refiere a las estimaciones de distancias, rumbos, direcciones de los vientos y localización de accidentes geográficos para posteriormente incorporarse a 
tal transmisión datos hidrográficos tan fundamentales para la navegación como los correspondientes a las sondas de los fondos $\operatorname{costeros}^{56}$.

De otra parte, por lo que se refiere al estudio de la red portuaria, los resultados obtenidos han resultado, de algún modo, más tímidos. Ciertamente, hemos podido establecer una cartografía altamente precisa de la mayor parte del litoral sur ibérico, desde el cabo de San Vicente hasta el cabo de Palos, localizando los principales hitos geográficos, puertos y fondeaderos atendidos por los navegantes que operaban en el golfo de Cádiz y en el mar de Alborán entre, grosso modo, 1480-1550/80. Este hecho es en sí mismo un logro, entendemos, meritorio, en la medida en que estos esfuerzos de representación cartográfica sistemática han de ser tenidos en cuenta para la comprensión global de las redes portuarias y del tráfico naval en los mares meridionales de la Península. En este caso, además, merece la pena mencionar que nos ha sido posible incorporar a esta cartografía toda una serie de pequeños lugares, en muchos casos de difícil identificación o mal conocidos y que fueron escenario de actividad naval continuada, aun a muy pequeña escala, sobre todo para la costa mediterránea del reino de Granada tras la conquista castellana y para el reino de Murcia. Sin embargo, el estudio de las jerarquías portuarias en estas costas a partir de las fuentes náuticas que hemos manejado, por sí solas, no ha deparado resultados excesivamente reveladores. El limitado valor cualitativo de las informaciones aportadas por estos documentos y tratados sobre la importancia de los puertos y surgideros reconocidos en ellos obliga a que, para una explotación intensiva de tales informaciones, haya de recurrirse a su análisis combinado junto con las aportadas por otras fuentes escritas, gráficas y arqueológicas. Algo que, por otra parte, se halla en la línea de las investigaciones desarrolladas en los últimos años sobre los territorios litorales del sur de la Península Ibérica y las dinámicas sociales desarrolladas en ellos entre el final de la Edad Media y los inicios de la Edad Moderna.

Cuando menos, ya concluyendo, creemos haber mostrado con el análisis de esta documentación náutica que la experiencia y la palabra del marino tiene mucho que decir para la investigación en la Historia marítima hispana medieval y moderna en ese período de la Era de los Descubrimientos. En una época fuertemente caracterizada por la intensificación de los contactos entre los ámbitos mediterráneo y atlántico en el Viejo Mundo y de expansión de la sociedad del Occidente cristiano medieval,

${ }^{56}$ Ese cambio progresivo en el conocimiento de los detalles necesarios para la navegación de cabotaje puede apreciarse bien en la práctica documentada de la contratación de marinos locales o veteranos en estas costas por mercaderes y patrones extranjeros para asegurar el acceso a los puertos de sus navíos en época bajomedieval, con anterioridad a que este tipo de saberes superase su nivel de normalización y difusión más allá del conocimiento transmitido de forma empírica y por vía fundamentalmente oral. Así, algunos ejemplos interesantes acerca del recurso por comerciantes y navegantes italianos a marinos y embarcaciones andaluzas y vascas en estas maniobras y travesías que afectaban a la Península Ibérica y a la conexión del Mediterráneo con el Atlántico en el siglo XV en HeERs, Jacques: "Le commerce des Basques en Méditerranée au XV' siècle (d'après les archives de Gênes)", Bulletin Hispanique (Burdeos) 57 (1955) 292-324/309, 316; GonzÁlez Arévalo, R.: "La costa del reino de Sevilla...”, pp. 315-316; IDEM: "Corso, comercio y navegación en el siglo XV: Castilla y las galeras mercantiles de Florencia", EEM, 34 (2011) 61-95/90. Estos aspectos también han sido puestos de manifiesto por Michel BochaCA en su conferencia "Del Mediterráneo al Atlántico: parla y representaciones marineras en la primera mitad del siglo XV", de pronta publicación [Cuadernos del Cemyr (San Cristóbal de La Laguna) 22 (2014)]. 
precisamente de cara al Atlántico, sin duda estos testimonios son de sumo interés para profundizar en los pormenores del ejercicio de la actividad náutica. Pero, yendo más allá, podemos ser conscientes de su extraordinario valor a la hora de arrojar luz sobre la evolución de estos espacios marítimos ibéricos y de la propia percepción que de ellos tuvieron las gentes que los practicaron y construyeron, material e intelectualmente, a lo largo de ese tiempo de extraordinarias transformaciones a caballo entre la Edad Media y la Edad Moderna. 